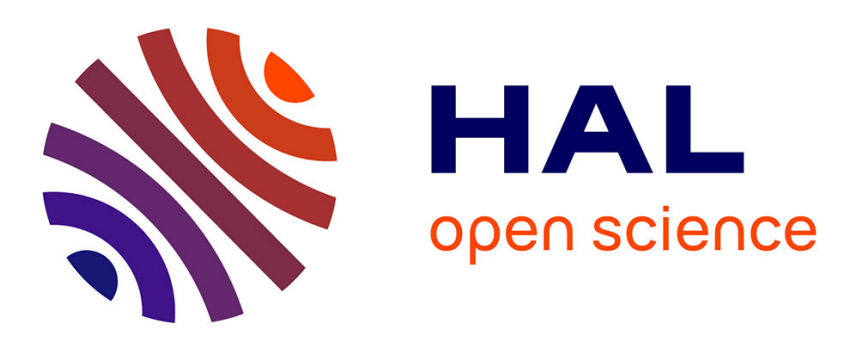

\title{
Finding buried metallic pipes using a non-destructive approach based on 3D time-domain induced polarization data
}

\author{
Zhenlu Shao, André Revil, Deqiang Mao, Deming Wang
}

\section{To cite this version:}

Zhenlu Shao, André Revil, Deqiang Mao, Deming Wang. Finding buried metallic pipes using a non-destructive approach based on 3D time-domain induced polarization data. Journal of Applied Geophysics, 2018, 151, pp.234-245. 10.1016/j.jappgeo.2018.02.024 · hal-02324220

\author{
HAL Id: hal-02324220 \\ https://hal.science/hal-02324220
}

Submitted on 23 Nov 2020

HAL is a multi-disciplinary open access archive for the deposit and dissemination of scientific research documents, whether they are published or not. The documents may come from teaching and research institutions in France or abroad, or from public or private research centers.
L'archive ouverte pluridisciplinaire HAL, est destinée au dépôt et à la diffusion de documents scientifiques de niveau recherche, publiés ou non, émanant des établissements d'enseignement et de recherche français ou étrangers, des laboratoires publics ou privés. 


\title{
Finding buried metallic pipes using a non-destructive approach based on 3D time-domain induced polarization data
}

\author{
Zhenlu Shao a,b,c, André Revil a,b,*, Deqiang Mao ${ }^{\mathrm{d}}$, Deming Wang ${ }^{\mathrm{c}}$ \\ a Université Grenoble Alpes, CNRS, IRD, IFSTTAR, ISTerre, Grenoble, France \\ b Université Savoie Mont Blanc, ISTerre, Chambéry, France \\ c School of Safety Engineering, China University of Mining and Technology, Xuzhou, Jiangsu, China \\ d School of Civil Engineering, Shandong University, 17922 Jingshi Rd, Jinan, Shandong 250061, China
}

\section{A R T I C L E I N F O}

\section{Article history:}

Received 13 August 2016

Received in revised form 10 December 2017

Accepted 26 February 2018

Available online 01 March 2018

\section{Keywords:}

Underground utilities

Pipe

Induced polarization

Inversion

\begin{abstract}
A B S T R A C T
The location of buried utility pipes is often unknown. We use the time-domain induced polarization method to non-intrusively localize metallic pipes. A new approach, based on injecting a primary electrical current between a pair of electrodes and measuring the time-lapse voltage response on a set of potential electrodes after shutting down this primary current is used. The secondary voltage is measured on all the electrodes with respect to a single electrode used as a reference for the electrical potential, in a way similar to a self-potential time lapse survey. This secondary voltage is due to the formation of a secondary current density in the ground associated with the polarization of the metallic pipes. An algorithm is designed to localize the metallic object using the secondary voltage distribution by performing a tomography of the secondary source current density associated with the polarization of the pipes. This algorithm is first benchmarked on a synthetic case. Then, two laboratory sandbox experiments are performed with buried metallic pipes located in a sandbox filled with some clean sand. In Experiment \#1, we use a horizontal copper pipe while in Experiment \#2 we use an inclined stainless steel pipe. The result shows that the method is effective in localizing these two pipes. At the opposite, electrical resistivity tomography is not effective in localizing the pipes because they may appear resistive at low frequencies. This is due to the polarization of the metallic pipes which blocks the charge carriers at its external boundaries.
\end{abstract}

(c) 2017 Elsevier B.V. All rights reserved.

\section{Introduction}

Population growth, economy development, and industrial expansion have led to a dramatic increase of the construction of underground infrastructures, especially buried pipes and cables used to satisfy the societies demand for light, heat, clean water, communication, and sewerage (Costello et al., 2007). As a result, the underground has become a maze of electrical cables, gas pipes, drainage, water pipes, telecommunication cables and other essential services infrastructures (Jeong and Abraham, 2004; Dziadak et al., 2009). In China, the total length of pipes used for supplying clean water, gas, and heat is $>1.7$ million $\mathrm{km}$ in 2015 and is currently increasing by 0.1 million $\mathrm{km}$ per year (Qi, 2016). However, due to the long history and the absence of comprehensive and accurate maps, the task of locating these buried pipes and cables is becoming increasingly important.

In the last few decades, various non-destructive methods have been applied to localize underground pipes. They include ground penetrating radar (Olhoeft, 2000; Tong, 1997; Bernstein et al., 2000), electromagnetic and radiofrequency line locators (Dziadak et al., 2009; Fedde and Patterson, 1988), magnetometers (Vickridge and Leontidis, 1997; Sun

\footnotetext{
* Corresponding author.

E-mail address: andre.revil@univ-smb.fr (A. Revil).
}

et al., 2011), acoustic location systems (Muggleton and Brennan, 2004), and infrared thermography (Costello et al., 2007; Wirahadikusumah et al., 1998). Resistivity-based methods (either through galvanometric or induction-based techniques) are not effective in localizing metallic pipes since metallic bodies can appear resistive at low frequencies due to their polarization (i.e., the secondary field exactly cancels out the primary field, e.g., Wong, 1979). Ground penetrating radar is most commonly used to detect underground pipes (Al-Nuaimy et al., 2000; Grandjean et al., 2000; Pettinelli et al., 2009; Ayala-Cabrera et al., 2011; Janning et al., 2012). However, in the case of conductive host materials (such as clay and saturated soils), the strong attenuation of high frequency electromagnetic waves greatly affects the penetration depth of GPR and drastically reduce its usefulness (Goodman, 1994). This is due to the small skin depths of electromagnetic disturbances at high frequencies in conductive environments.

We introduce in this paper a novel strategy using time-domain induced polarization data to locate buried metallic pipes especially in conductive environments for which the ground penetrating radar is ineffective. Time domain induced polarization is based on injecting a primary current in the ground, then this current is shut down, and we measure remotely the secondary voltage associated with the reversible accumulation of electrical charges in the ground. Typically the primary 
current is injected on two current electrodes A and B and the voltages measured on two potential electrodes $\mathrm{M}$ and $\mathrm{N}$. We will introduce a new linear approach for time domain induced polarization tomography that is faster than the classical non-linear approach used to perform a tomography of the chargeability.

In this paper, we first describe the underlying physics associated with the induced polarization of metallic pipes in terms of the formation of a secondary source current density. Then, a modified time-domain induced polarization method is discussed in the context of buried metallic pipes localization. Two sandbox experiments are performed: one with a horizontal copper pipe and the other with an inclined stainless steel pipe to demonstrate the applicability of the method in conductive environments. So there are three new points that are described in this paper namely (1) a new inversion procedure for time-domain induced polarization, (2) a new strategy to find metallic pipes in conductive ground, and (3) a validation of these approaches using synthetic and sandbox experiments.

\section{Basic principles}

Induced polarization is a non-intrusive method looking at localizing low-frequency $(<1 \mathrm{kHz})$ polarization mechanisms in conductive materials (Figs. 1 and 2). These low-frequency polarization mechanisms are associated with the reversible storage of charge carriers during the application of a primary electrical field or electrical current and their diffusion in their concentration gradients. The method was initially developed by Schlumberger (1920). The history of induced polarization method can be found in Seigel et al. (2007) for ore prospection and Revil et al. (2012) for non-metallic porous materials. Nowadays, induced polarization is widely used to explore ore deposits, such as porphyry coppers, bedded lead/zinc and sulphide-related gold (Loeb and Bertin, 1976; Seigel et al., 2007; Kemna et al., 2012; Revil et al., 2012). It is much more effective than electrical resistivity tomography, which cannot be used to localize disseminated ores because they appear resistive at low frequencies (see Wong, 1979; Revil et al., 2015a, b). The induced polarization method is also used in environmental geosciences for contaminant plume delineation and remediation (Vanhala et al., 1992; Kemna et al., 2004; Gazoty et al., 2012), facies differentiation (Slater and Lesmes, 2002; Kemna et al., 2004), and the monitoring of geochemical changes in porous media (Doetsch et al., 2015).

In time-domain induced polarization, a primary electrical current is injected over a certain time in the ground between two current electrodes A and B (Fig. 2). Such current pair is called a current bipole in the following. Then, this current is suddenly shut down and a secondary electrical field is generated and measured between two potential electrodes $\mathrm{M}$ and $\mathrm{N}$ (or a set of potential electrodes) for a period of time (Fig. 2). As a first approximation, the metallic object in the ground behaves as a capacitor that gets charged during the application of the primary current and is discharging in the conductive ground after the shutdown of the primary current (Kemna et al., 2012). The polarization mechanisms associated with this "chargeability" of the metallic object are summarized in Fig. 1. After the shut-down of the primary current or electrical field, a secondary field can be observed (see Mao and Revil, 2016, and Fig. 2). It is this secondary electrical field that we are interested to study in this paper.

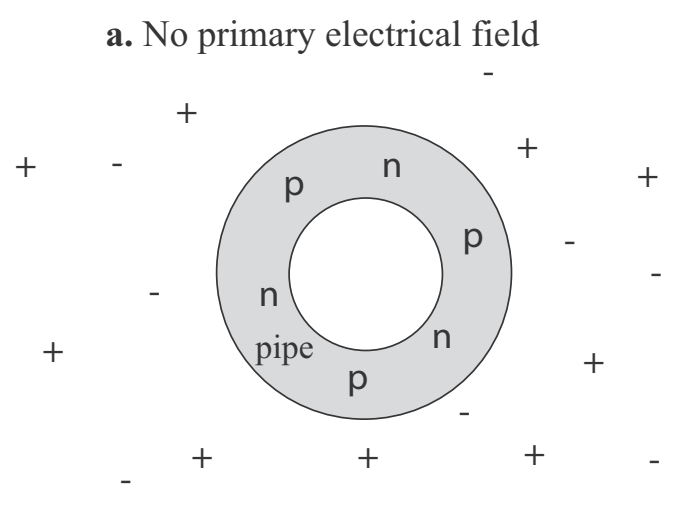

b. Primary electrical field (short time)

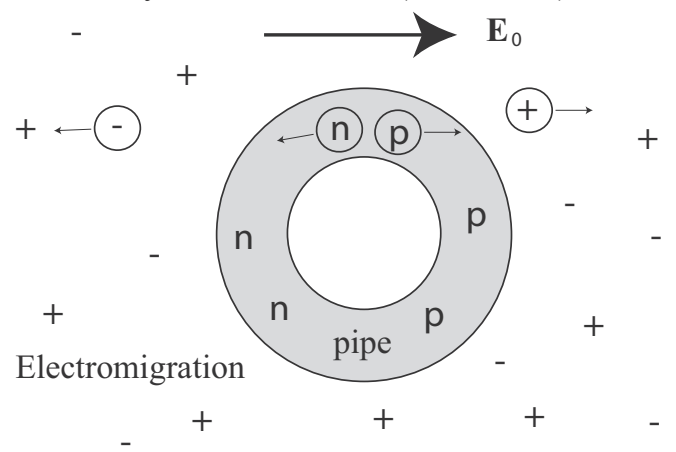

c. Primary electrical field (long time)

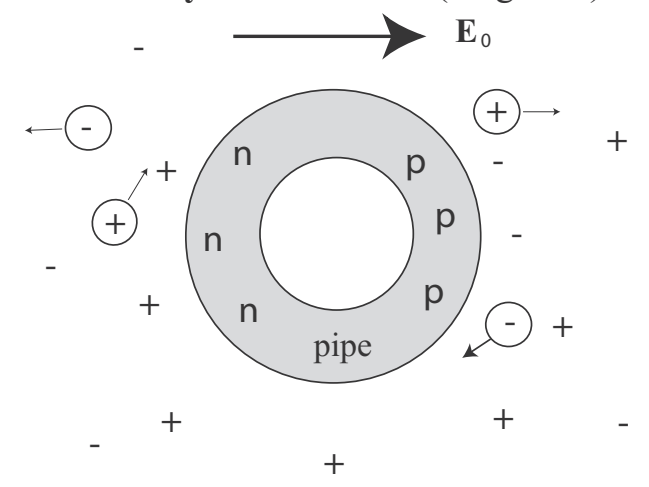

d. Removal of the primary electrical field

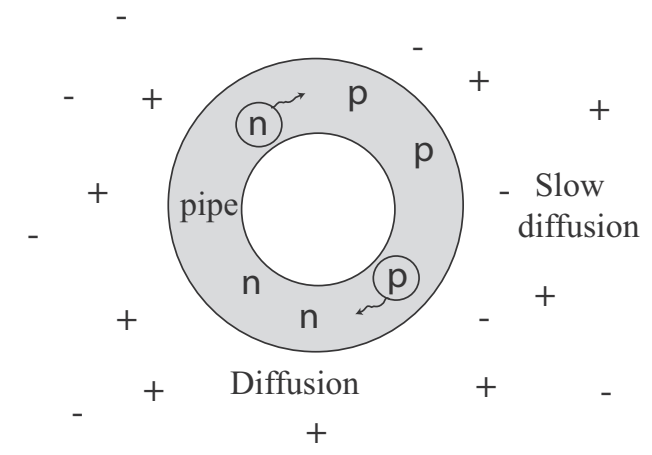

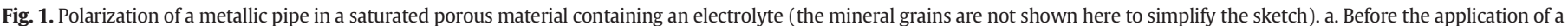

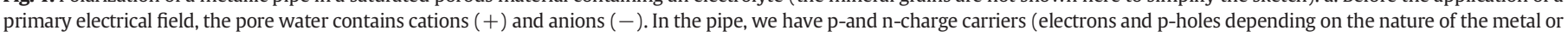

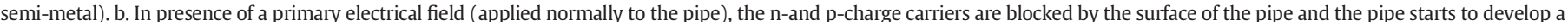

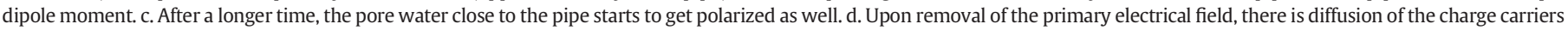

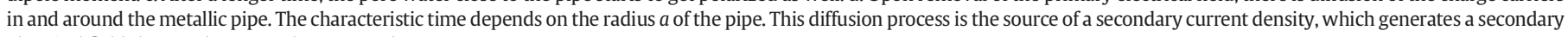
electrical field that can be remotely measured. 
a) Sequence for a single measurement

Measured voltage
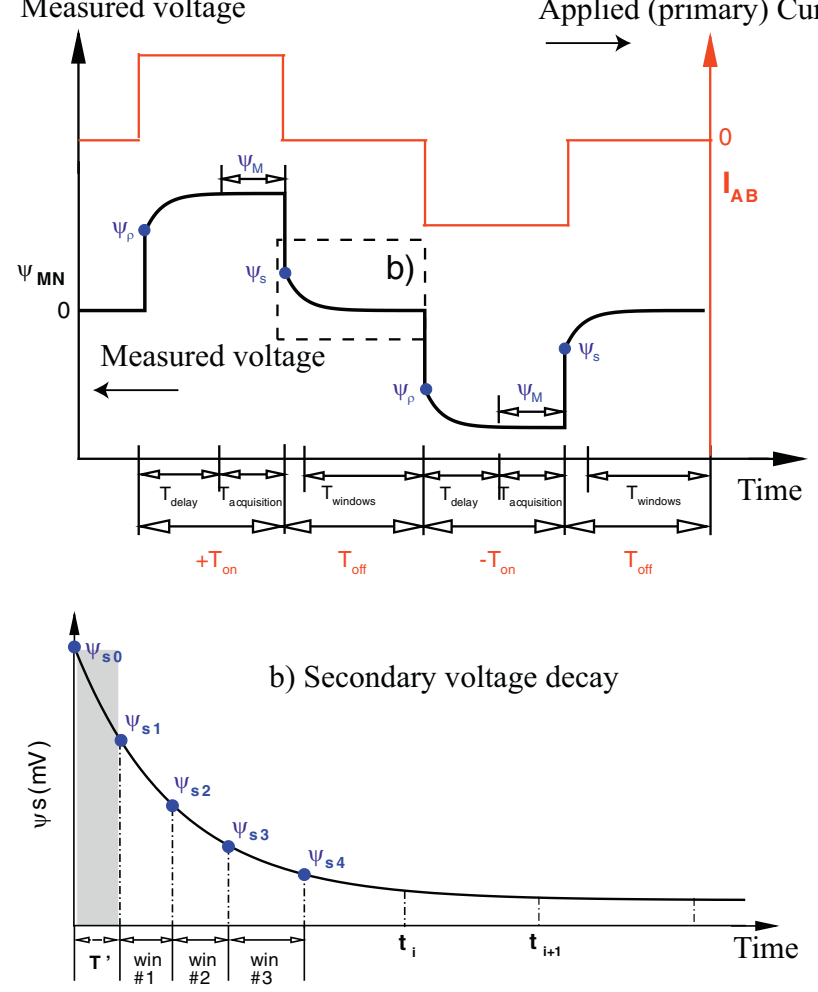

Fig. 2. Principle of time domain induced polarization. Traditionally, in time-domain induced polarization measurement, we use four electrodes with A and B denoting the current electrodes and $\mathrm{M}$ and $\mathrm{N}$ the voltage electrodes, respectively. $\mathrm{a}$. The red curve denotes the current injection from electrode $A$ to electrode $B$ (positive) and from electrode $B$ to electrode $A$ (negative). A single measurement sequence is characterized by 4 periods: $+\mathrm{T}_{\text {on }}, \mathrm{T}_{\text {off }},-\mathrm{T}_{\text {on }}$ and $\mathrm{T}_{\text {off }}$. Each $\mathrm{T}_{\text {on }}$ period consists of one $\mathrm{T}_{\text {delay }}$ and one $\mathrm{T}_{\text {acquision }}$ period. The potential measured at the two voltage electrode $\mathrm{M}$ and $\mathrm{N}$ is shown by the solid black curve. The potential at steady state of the curve is recorded to determine the electrical resistivity. b. The secondary voltage decay $\psi_{\mathrm{s}}$ is measured after the primary current is shut-down. After an initial delay period $T^{\prime}$ (gray area), the secondary voltage is measured with ten windows using an ABEM SAS1000 defined for distinct different time intervals. This secondary voltage distribution is actually measured on a number of electrodes $\mathrm{M}$ for a single electrode $\mathrm{N}$ used as the reference. This distribution is then inverted to get the source location of the primary current density. (For interpretation of the references to colour in this figure legend, the reader is referred to the web version of this article.)

\section{Time domain induced polarization}

\subsection{Background}

As indicated by Revil et al. (2015a, b), the secondary electrical field is associated with a secondary source current density. This secondary current density is itself associated with the diffusion of the charge carriers once the primary current or electrical field has been shut down (Fig. 1). The principle of time-domain induced polarization is underlined in Fig. 2. In a traditional time-domain induced polarization survey, a large number of current injection pairs $[A, B]$ are used, which is timeconsuming, and the electrical field is measured only on few pairs of electrodes $\mathrm{M}$ and $\mathrm{N}$ at a time. In our new approach (following Mao and Revil, 2016), the current injection pairs are reduced to a few bipoles, but we increase drastically the number of potential electrodes [M, N] used for measuring the secondary voltage distribution. One of the electrodes (for instance $\mathrm{N}$ ) serves as a unique reference for all the measurements of the secondary voltages/potentials and all the time (in other words we have a high number of electrodes $M$ used to monitor the decay of the secondary voltages and the voltage measurements are
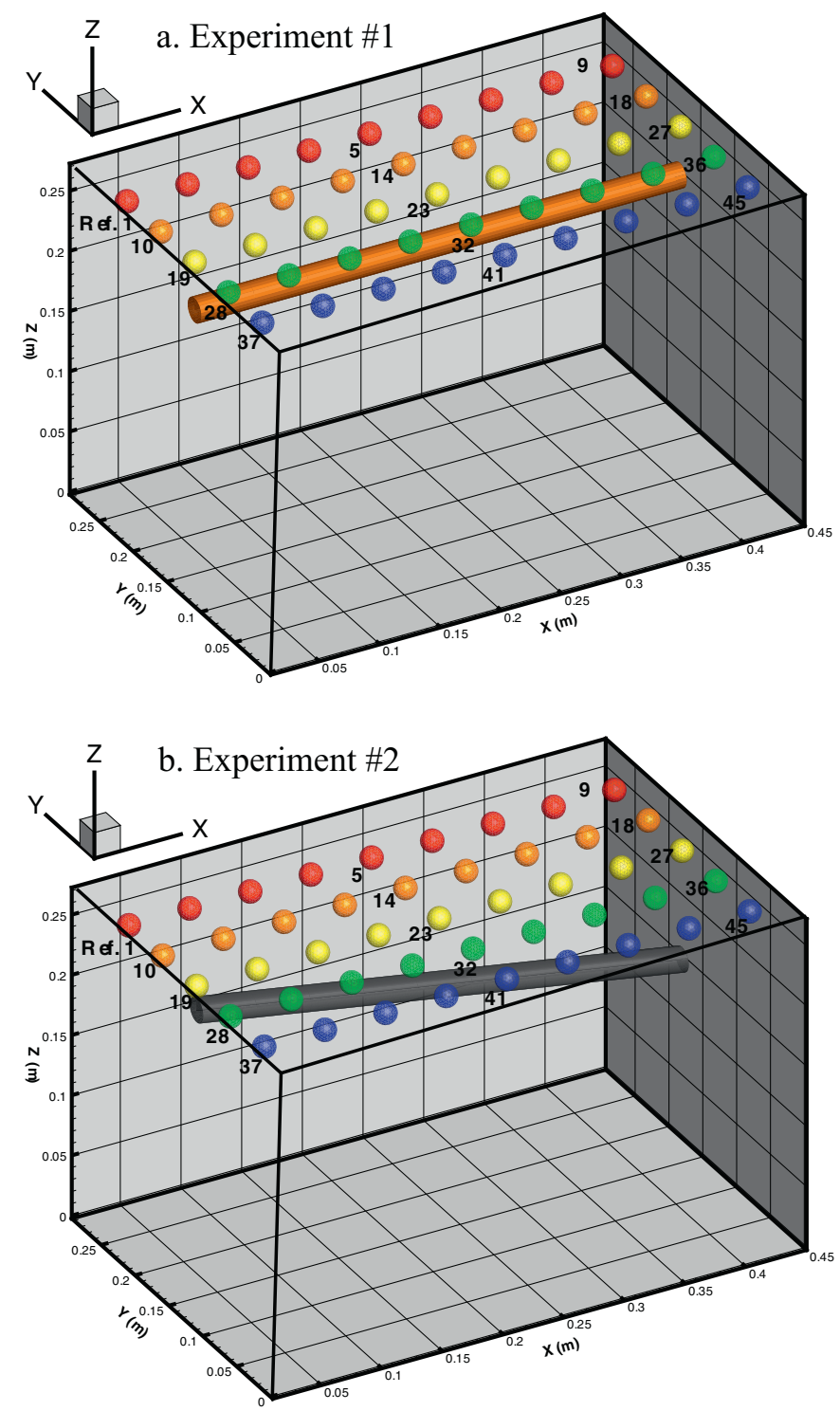

Fig. 3. Sketch of the sandbox used for the two experiments. a. Configuration of Experiment \#1 with a horizontal copper pipe. The brassy cylinder denotes the copper pipe. The spheres represent the electrodes on the surface of the sandbox. Ref denotes the reference electrode for the set of electrodes used for the secondary potential measurements. b. Sketch of Experiment \#2 with an inclined stainless steel pipe. The dark gray cylinder denotes the stainless steel pipe. The angle of the pipe with respect to the horizontal $\mathrm{x}-\mathrm{y}$ plane is $10^{\circ}$.

Table 1

Parameters used for the data collection of the two sandbox experiments.

\begin{tabular}{lclllll}
\hline $\begin{array}{l}\text { Injected } \\
\text { current }\end{array}$ & $\mathrm{T}_{\text {on }}$ & $\begin{array}{l}\text { Prim. acq. } \\
\text { time }\end{array}$ & $\begin{array}{l}\text { Initial } \\
\text { delay }\end{array}$ & $\begin{array}{l}\text { Base IP } \\
\text { interval }\end{array}$ & $\begin{array}{l}\text { No. of } \\
\text { windows }\end{array}$ & $\begin{array}{l}\text { Total time for all } \\
\text { the windows }\end{array}$ \\
\hline $5 \mathrm{~mA}$ & $1 \mathrm{~s}$ & $0.1 \mathrm{~s}$ & $0.03 \mathrm{~s}$ & $0.02 \mathrm{~s}$ & 8 & $5.1 \mathrm{~s}$ \\
\hline
\end{tabular}

Table 2

Parameters of the 8 windows associated with the collection of the time-domain induced polarization data for the two sandbox experiments.

\begin{tabular}{lllllllll}
\hline Window number & 1 & 2 & 3 & 4 & 5 & 6 & 7 & 8 \\
\hline Duration of each window (s) & 0.02 & 0.04 & 0.08 & 0.16 & 0.32 & 0.64 & 1.28 & 2.56 \\
\hline
\end{tabular}


a. Synthetic test: Map of the electrical potential distribution

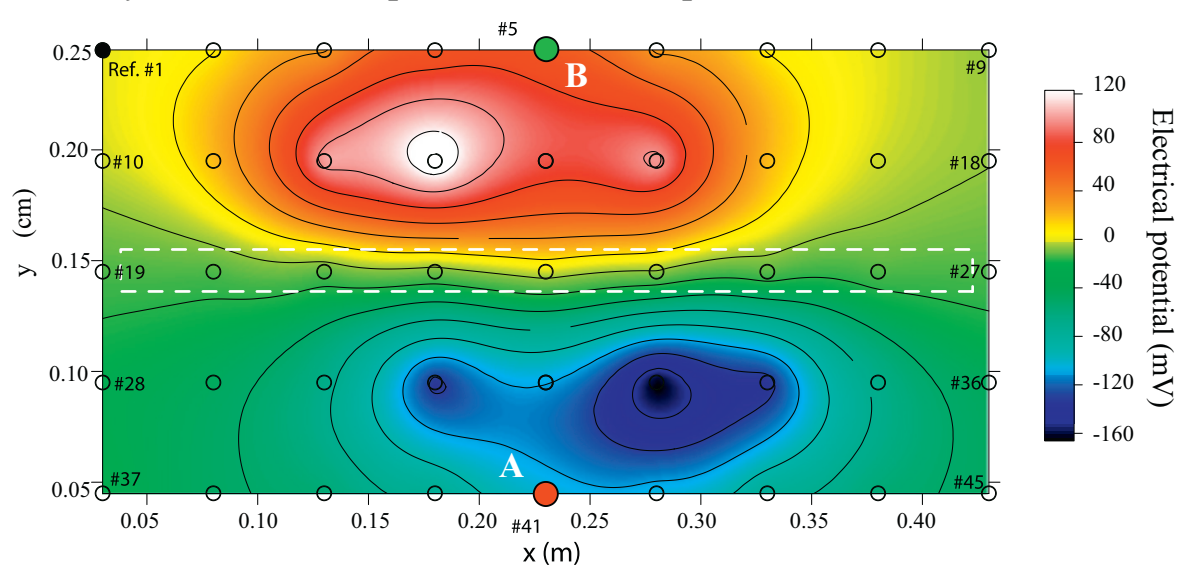

b. Synthetic test: Iterative localization of a buried source of current
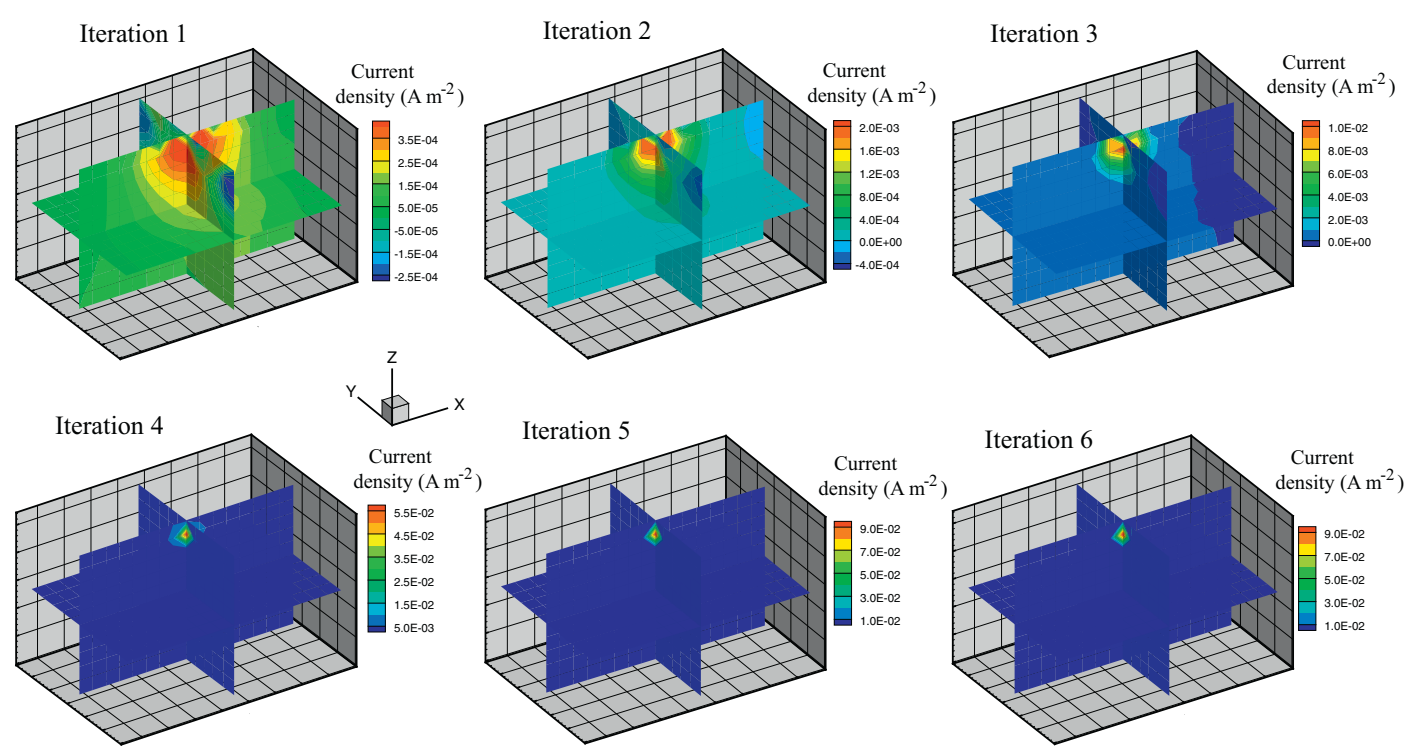

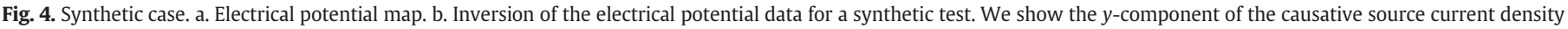

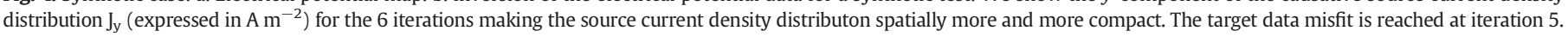

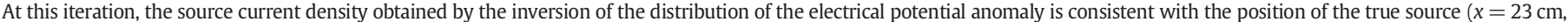
$y=14.5 \mathrm{~cm}, z=22 \mathrm{~cm})$. Furthermore, the value of the inverted source current density $\left(0.09 \mathrm{~A} \mathrm{~m}^{-2}\right)$ is close to that set up in the synthetic model $\left(0.1 \mathrm{~A} \mathrm{~m}^{-2}\right)$.

referenced to one electrode $\mathrm{N}$ ). Therefore, a lot of time can be saved when conducting such a survey by comparison with a classical induced polarization survey. This type of acquisition is similar in treating the secondary voltage as an equivalent transient self-potential signal.

Apart from the acquisition of the data, the inversion algorithm used below also differs from that used in the traditional time-domain induced polarization method. In the classical approach, we solve a nonlinear problem in order to image the chargeability from the secondary voltages. In the new approach, we are focusing on the inversion of the secondary source current density. The relationship between the secondary voltages/potentials and the secondary current density is linear (as discussed below). Since the secondary voltage is associated with a secondary source current density caused by the metallic pipe (Fig. 1), the inversion approach focuses in obtaining the source current density rather than the chargeability. Our goal is indeed to focus on the localization of the pipe (through a tomography of the secondary source current density) and not to determine a material property (such as the chargeability).

We discuss now the equations describing the underlying physics of the problem. After the primary current is shut down, the total current density $\mathbf{J}$ (expressed in $\mathrm{A} \mathrm{m}^{-2}$ ) can be written as the sum of a conduction current density (given by Ohm's law) and a source current density of diffusional nature (e.g., Mao and Revil, 2016),

$\mathbf{J}=\sigma \mathbf{E}+\mathbf{J}_{\mathbf{s}}$

where $\mathbf{E}$ denotes the secondary electrical field (in $\mathrm{V} \mathrm{m}^{-1}$ ), $\sigma$ denotes the electrical conductivity of the porous material (in $\left.\mathrm{S} \mathrm{m}^{-1}\right)(\rho=1 / \sigma$ is the resistivity expressed in $\Omega \mathrm{m}$ ), and $\mathbf{J}_{\mathbf{s}}$ (in $\mathrm{A} \mathrm{\textrm {m } ^ { - 2 }}$ ) denotes the secondary source current density. In the quasi-static limit of the Maxwell equations, $\nabla \times \mathbf{E}=0$, and therefore $\mathbf{E}=-\nabla \psi$ (induction neglected) where $\psi$ (in $\mathrm{V}$ ) denotes the secondary voltage or electrical potential. It is this potential that is remotely measured at the voltage electrodes after the shutdown of the primary current density. The secondary current density $\mathbf{J}_{S}$ is due to the formation of charge accumulations during the primary current injection on the current electrode pair [A, B]. In essence, it is due to the gradient of the chemical potential of the charge carriers (e.g., Leroy et al., 2008, and Revil et al., 2015a, b, 2017a, b, and see Fig. 1).

The conservation of charge corresponds to the continuity equation for the current density. In the low-frequency limit of the Maxwell 

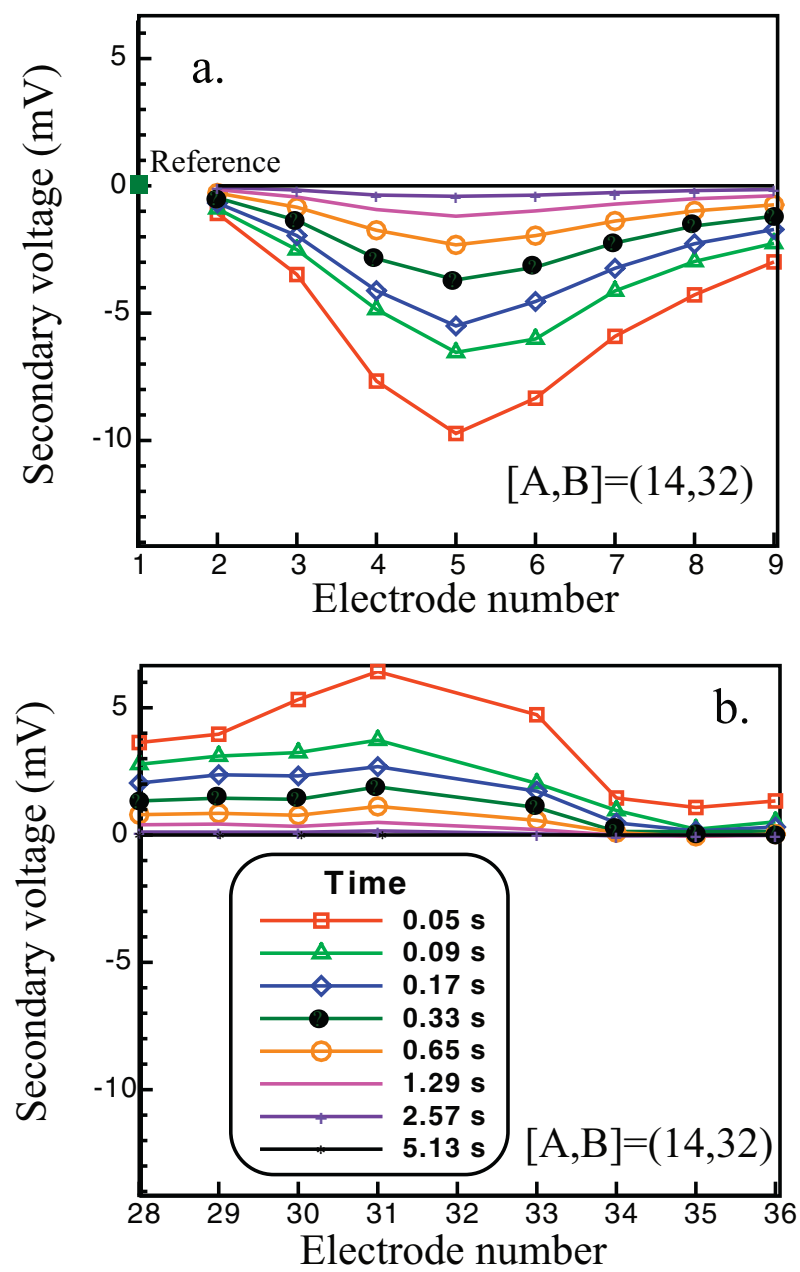

Fig. 5. The secondary voltage distribution at few selected electrodes as a function of time for snapshot 5 in Experiment \#1 (current electrode pair $[A, B]=[14,32]$ ). Electrode 1 represents the reference (its potential is always zero).Time starts after the shutdown of the primary current. All the data are also referenced with respect to a temporal reference, i.e., the secondary voltage obtained at time $t=5.13 \mathrm{~s}$ after the shutdown of the primary current. We consider that at this elapsed time, the secondary voltage distribution has vanished.

equations, it is written as (e.g., Mao and Revil, 2016)

$$
\nabla \cdot \mathbf{J}=0
$$

Combining Eqs. (1) and (2) yields the following Poisson's equation for the secondary electrical potential,

$\nabla \cdot(\sigma \nabla \psi)=\nabla \cdot \mathbf{J}_{\mathbf{s}}$

This equation is similar to the equation used to solve self-potential problem in geophysics. In the self-potential method, the electrical potential distribution is remotely measured (e.g., at the ground surface) and associated with in situ source of current $\mathbf{J}_{s}$, which can be of diffusive nature (Ikard et al., 2012), electrokinetic nature (Soueid Ahmed et al., 2013), or of thermal nature (Revil et al., 2013). It is also similar to the equation solved in medical imaging for electroencephalography to determine what part of the brain is active at a given time or to localize the source of epilepsy (Grech et al., 2008).

\subsection{Data inversion}

The electrical potential solution of Eq. (3) can be written also into an integral form, which, once discretized (e.g., with the finite element method), can be written in a linear form (Grech et al., 2008; Rittgers et al., 2013; Mao and Revil, 2016)

$\mathbf{d}=\mathbf{K} \mathbf{m}$,

where $\mathbf{d}$ denotes the vector of secondary electrical potential data, $\mathbf{K}$ denotes the discretized form of the kernel (formed by a collection of Green functions, which can be easily computed as long as the resistivity distribution is known, for instance through electrical resistivity tomography), $\mathbf{m}$ is the vector of source current density time the volume of each cell. The vector $\mathbf{m}$ is the model vector we want to determine.

The determination of the kernel is the most computationally intensive step in this approach (see for instance Grech et al., 2008, for details for encephalographic problems). Here, we use the finite element code Comsol Multiphysics 5.0 to compute the kernel by placing elementary dipoles in the 3 principal directions $x, y$, and $z$ (Jardani et al., 2008). Since, according to Eq. (3), the secondary electrical potential field is affected by the electrical conductivity distribution, the electrical conductivity distribution is included in the computation of the elements of the kernel (Mao et al., 2015). Electrical resistivity tomography can be used to independently obtain this information. The computation of the kernel also accounts for the boundary conditions (insulating boundaries in the case discussed below).

After establishing the kernel, we consider the following cost function to be minimized:

$\mathbf{P}^{\lambda}(\mathbf{m})=\left\|\mathbf{W}_{\mathrm{d}}\left(\mathbf{K} \mathbf{m}-\mathbf{d}_{\mathrm{obs}}\right)\right\|^{2}+\lambda\left\|\mathbf{W}_{\mathrm{m}} \mathbf{m}\right\|^{2}$

where the optimal model vector is given by $\mathbf{m}^{*}=\operatorname{argmin}\left[\mathbf{P}^{\lambda}(\mathbf{m})\right]$. The first term of Eq. (5) is called the data misfit term and the second term is the regularizer. In this equation, the matrix $\mathbf{W}_{\mathrm{d}}$ is related to the data covariance matrix (in absence of information regarding the electrical potential measurements, it is taken as the identity matrix). The vector $\mathbf{d}_{\text {obs }}$ denotes the electrical potential data measured at each electrode $\mathrm{M}$ (secondary voltages). The parameter $\lambda$ denotes the regularization parameter (under the constraint that $0<\lambda<\infty$ ) and is used to balance the data misfit term and the regularizer. Various methods exist to optimize this parameter (see details in Grech et al., 2008). The matrix $\mathbf{W}_{\mathrm{m}}$ denotes the weighting matrix used to ensure a stable result. It is related to the model covariance matrix. In this paper, identity matrix I is used, which means that we use the minimum norm approach to regularize the inverse problem.

As pointed out by Jardani et al. (2008), without the use of a depth weighting function the inversion of the surface electrical potential data is likely to generate a shallow source current density distribution, i.e. close to the position of the electrodes. Therefore, a depth weighting matrix is usually applied to the kernel during inversion to counteract the sensitivity of the kernel matrix to near-surface model parameters and is given by the following relationship:

$\boldsymbol{\Lambda}=\operatorname{diag}\left(\sum_{\mathrm{j}=1}^{\mathrm{N}} \mathbf{K}_{\mathrm{ij}}^{2}\right)^{1 / 4}$,

where, "diag" refers to a diagonal matrix and $N$ is the number of measured electrical potential data ( $\mathbf{d}$ the data vector has a dimension of $N$ ).

The minimum support (MS) method (see Last and Kubik, 1983) is used in this paper to compact the spatial support of source current density, i.e., to find one model $\mathbf{m}$ with the minimum spatial volume of source currents. Thus, a new diagonal weighting matrix is established:

$\mathbf{\Omega}=\operatorname{diag}\left(\frac{\boldsymbol{\Lambda}_{\mathrm{kk}}^{2}}{\mathbf{m}_{\mathrm{k}-1}^{2}+\beta^{2}}\right)^{1 / 2}$ 
where $\mathbf{m}_{\mathrm{k}-1}$ is the source current density at iteration $\mathrm{k}-1, \beta$ is a small threshold number. The solution of the problem (corresponding to the minimum of the cost function) is given by

$$
\mathbf{m}^{*}=\left[\mathbf{K}^{* \mathrm{~T}}\left(\mathbf{W}_{\mathrm{d}}^{\mathrm{T}} \mathrm{W}_{\mathrm{d}}\right) \mathbf{K}^{*}+\lambda\left(\mathbf{W}_{\mathrm{m}}^{\mathrm{T}} \mathbf{W}_{\mathrm{m}}\right)\right]^{-1} \cdot\left[\mathbf{K}^{* \mathrm{~T}}\left(\mathbf{W}_{\mathrm{d}}^{\mathrm{T}} \mathbf{W}_{\mathrm{d}}\right) \mathbf{d}_{\mathrm{obs}}\right],
$$

where $\mathbf{K}^{*}=\mathbf{K} \boldsymbol{\Omega}^{-\mathbf{1}}$ and $\mathbf{m}^{*}=\boldsymbol{\Omega} \mathbf{m}$ denote a normalized kernel and a normalized model vector, respectively. Once the algorithm has converged, the retrieved source current density must be transformed back to get an unscaled current density using $\mathbf{m}=\mathbf{\Omega}^{-\mathbf{1}} \mathbf{m}^{*}$. Such an approach was used in several of our previous works for self-potential problems (see details in Rittgers et al., 2013; Haas et al., 2013; Mao and Revil, 2016). It has never been used for induced polarization.

\section{Sandbox experiments}

\subsection{Experimental setup}

The plastic tank used for this experiment has the following dimensions $0.46 \mathrm{~m} \times 0.29 \mathrm{~m} \times 0.27 \mathrm{~m}$. It was filled with a well-calibrated water-saturated quartz sand. The sand has the following characteristics: mean grain diameter and standard deviation $130 \pm 20 \mu \mathrm{m}$, composition $95 \% \mathrm{SiO}_{2}, 4 \% \mathrm{KSi}_{3} \mathrm{AlO}_{8}$ and $<1 \% \mathrm{NaAlSi}_{3} \mathrm{O}_{8}$, and a porosity $0.34 \pm 0.02$ (see details in Naudet and Revil, 2005). Tap water was used to saturate the sand. The electrical conductivity of the tap water was measured to be $0.49 \mathrm{mS} \mathrm{cm}^{-1}$ (at $25^{\circ} \mathrm{C}$ ) i.e., its resistivity was $20.4 \Omega \mathrm{m}$. Since the formation factor of this sand was 3.6 (see Naudet and Revil, 2005), the resistivity of water-saturated sand was around $74 \Omega \mathrm{m}$.

Two experiments were performed. For these two experiments (labeled Experiment \#1 and Experiment \#2 below), a total of 45 stainless steel electrodes were arranged on the top surface of the sandbox forming a set of five lines (Fig. 3). The electrodes were inserted in the sand at a depth of $\sim 1 \mathrm{~cm}$ and with a horizontal spacing of $5 \mathrm{~cm}$. Electrode \#1 was used as reference (electrode $\mathrm{N}$ ) for all the measurements of the secondary voltages and all times.

In Experiment \#1, a copper pipe (diameter $2 \mathrm{~cm}$, length $40 \mathrm{~cm}$ ) was buried horizontally inside the tank (Fig. 3a). The depth of the pipe was therefore constant and equal to $5 \mathrm{~cm}$. The pipe was located from $x=$
$0.03 \mathrm{~m}$ from the left border of the tank to $x=0.43 \mathrm{~m}$, from $y=0.135 \mathrm{~m}$ to $y=0.155 \mathrm{~m}$ and from $z=0.21 \mathrm{~m}$ to $z=0.23 \mathrm{~m}$ (see the brassy cylinder in Fig. 3a). In Experiment \#2, an inclined stainless steel pipe (diameter $2 \mathrm{~cm}$, length $40 \mathrm{~cm}$ ) was buried in the tank with the inclination angle of 10 degrees with the horizontal direction (Fig. 3b). The depth was $3 \mathrm{~cm}$ at the left end, and $10 \mathrm{~cm}$ at the right end.

\subsection{Data acquisition}

As stated in Section 3, the data collection approach applied in this paper is different from the traditional one. A common reference for each measurement of the secondary voltage is used (electrode \#1). A total of 9 current bipoles were conducted in Experiment \#1 and 7 current bipoles in Experiment \#2. Each test was characterized by a single current bipole $[A, B]$ for the application of the primary current.

In Experiment \#1, 9 current electrode pairs located at the two sides of the pipe in horizontal direction ( $y$-direction) are used, i.e., $[\mathrm{A}, \mathrm{B}]=$ $[10,28],[11,29],[12,30],[13,31],[14,32],[15,33],[16,34],[17,35]$ and $[18,36]$. In Experiment \#2, 7 current injection pairs are used with $[A, B]=[2,38],[3,39],[4,40],[5,41],[6,42],[7,43]$ and $[8,44]$. These 7 pairs were chosen because the distance between $[A, B]$ is larger. A larger $[A, B]$ can generate a deeper electrical field, which would reach the inclined stainless steel pipe. Furthermore, the current electrode pairs [1, 37] and $[9,45]$ were not included because that electrode \#1 was the reference and the stainless steel pipe was not present between each pair.

For each current injection test, 42 electrical potential data were collected with an ABEM SAS1000 with respect to the reference electrode and the potential for the two current injection electrodes were not measured. Therefore, a total of 378 and 294 measurements were collected in these two experiments, respectively. For each test, the current injection duration was setup to $1.0 \mathrm{~s}$. The magnitude of the injected current was fixed to $5 \mathrm{~mA}$ in the first experiment. Since the distance between [A, $B]$ in Experiment \#2 was larger than that in the first one, we need a higher current to excite the pipe. We increased the current to $20 \mathrm{~mA}$ in the second experiment. In field conditions, there is no problem to increase the current up to $200 \mathrm{~mA}$ and to use more bipoles to localize the buried pipes. The present experiments should be seen as a proof-ofconcept of this new approach.

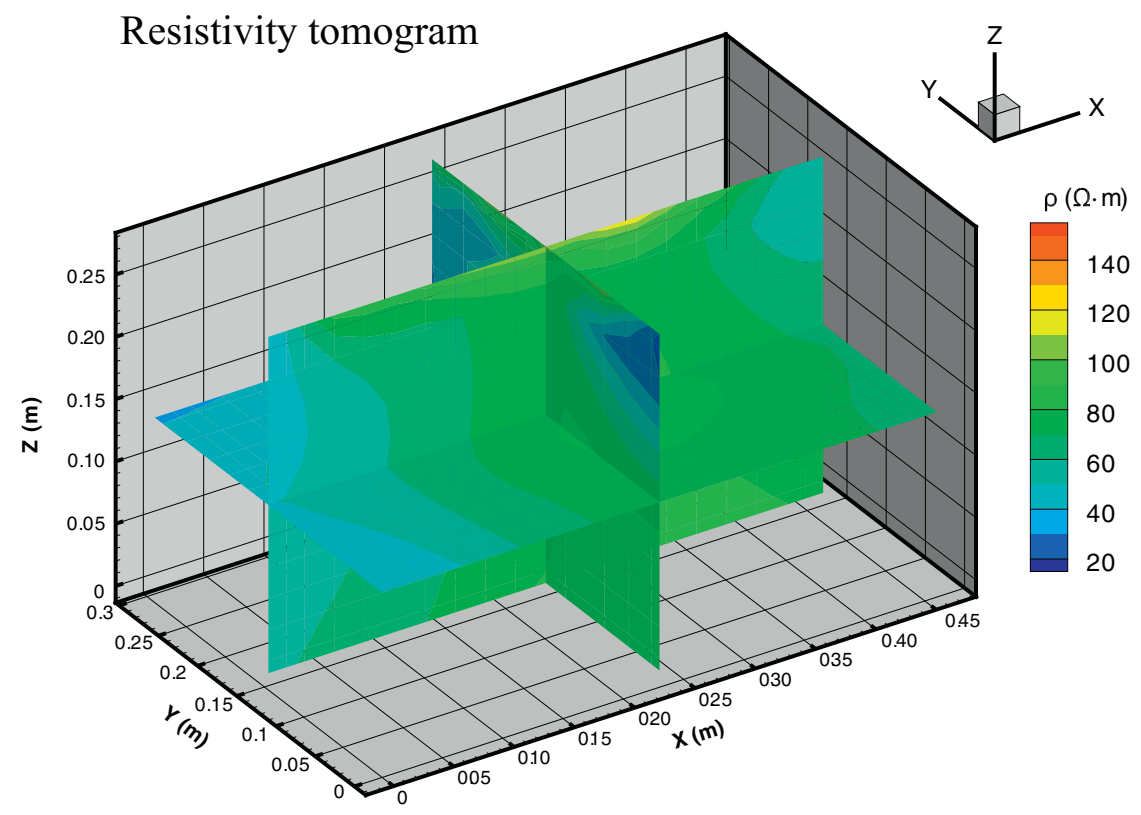

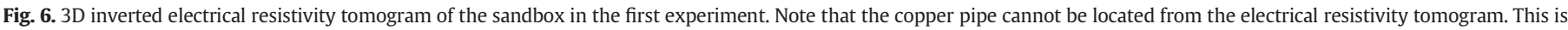

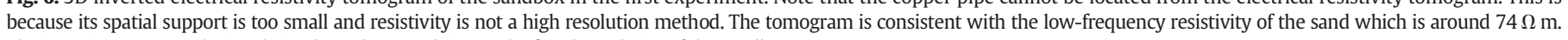
The inversion respects the insulating boundary condition at the four boundaries of the sandbox. 
The initial delay used to start measuring the secondary voltages was set up to $0.03 \mathrm{~s}$ (i.e., a dead time of $30 \mathrm{~ms}$ ) to avoid electromagnetic effects (see Table 1). A total of 8 windows were employed to measure the decay of the secondary voltage after this deadtime has ended (Fig. $2 \mathrm{~b}$ show a sketch of the sampling of the secondary voltage decay after the shutdown of the primary current). The smallest window was characterized by a duration of $0.02 \mathrm{~s}$ and the maximum window had a duration of $2.56 \mathrm{~s}$ (see Table 2). The total time for all the windows was fixed to $5.1 \mathrm{~s}$.

\subsection{Synthetic test}

Before the inversion of the laboratory data, we used the finite element code Comsol Multiphysics 5.0 to build a numerical model of the tank (accounting for the insulating boundary conditions on all the external surfaces). The geometry used in the model is the same as the tank used in the laboratory experiment described hereinafter, i.e., $46 \mathrm{~cm} \times 29 \mathrm{~cm} \times 27 \mathrm{~cm}$. The resistivity of the material inside the tank is arbitrarily set up to $100 \Omega \mathrm{m}$. A source current density $\left(J_{\mathrm{x}}=0 \mathrm{~A} \mathrm{~m}^{-2}, \mathrm{~J}_{\mathrm{y}}=0.1 \mathrm{~A} \mathrm{~m}^{-2}, J_{\mathrm{z}}=0 \mathrm{~A} \mathrm{~m}^{-2}\right)$ is located at the source position $x=23 \mathrm{~cm}, y=14.5 \mathrm{~cm}$, and $z=22 \mathrm{~cm}$ with a magnitude of $0.1 \mathrm{~A} \mathrm{~m}^{-2}$. Then, we solved numerically Eq. (3) with the finite element approach to compute the electrical potential distribution everywhere.

Then, we simulated the acquisition of the resulting electrical potential data shown in Fig. 4a (in other words, we sampled the electrical potential at the position of the electrodes). The potential at the reference electrodes (electrode \# 1 is used as a zero potential) was removed to the electrical potential collected at each electrode. Finally, the kernel matrix was calculated using the resistivity data (constant resistivity here), the position of these electrodes, and the insulating boundaries of the tank. The inversion of the data was performed with Matlab using the algorithm underlined in Section 3.2.

Fig. 4a shows the surface map of the computed electrical potential distribution, from which we can see the anomaly is generated by the synthetic bipole source current. Fig. $4 \mathrm{~b}$ shows the iterative compaction procedure of the source current density ( $y$-component) iteration by iteration. The spatial distribution of the source current density is shown at iterations 1 to 6 in the compaction/inversion process. The source current density concentrates step by step closer and closer to the true

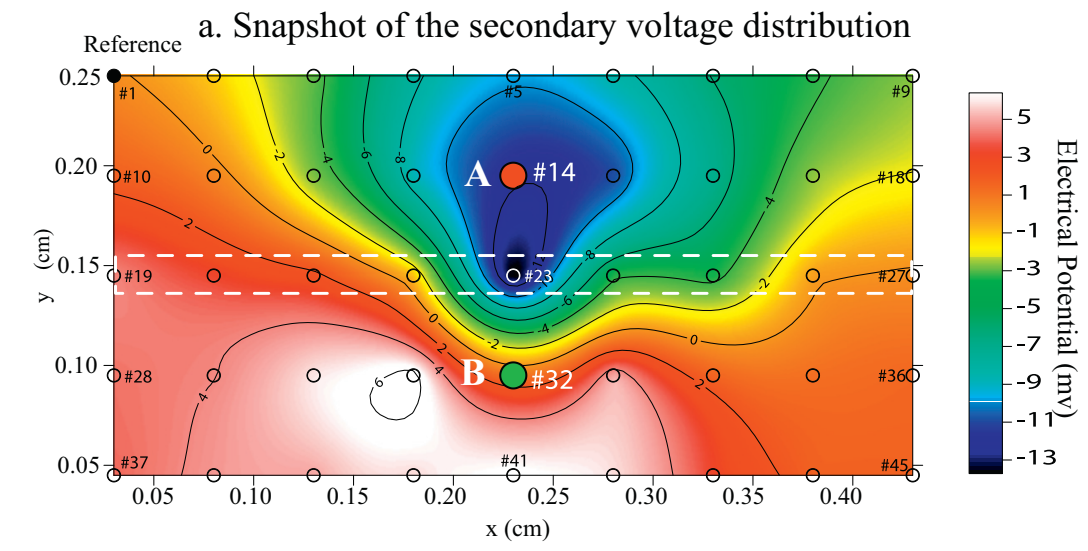

b. Iterative inversion of the source current density
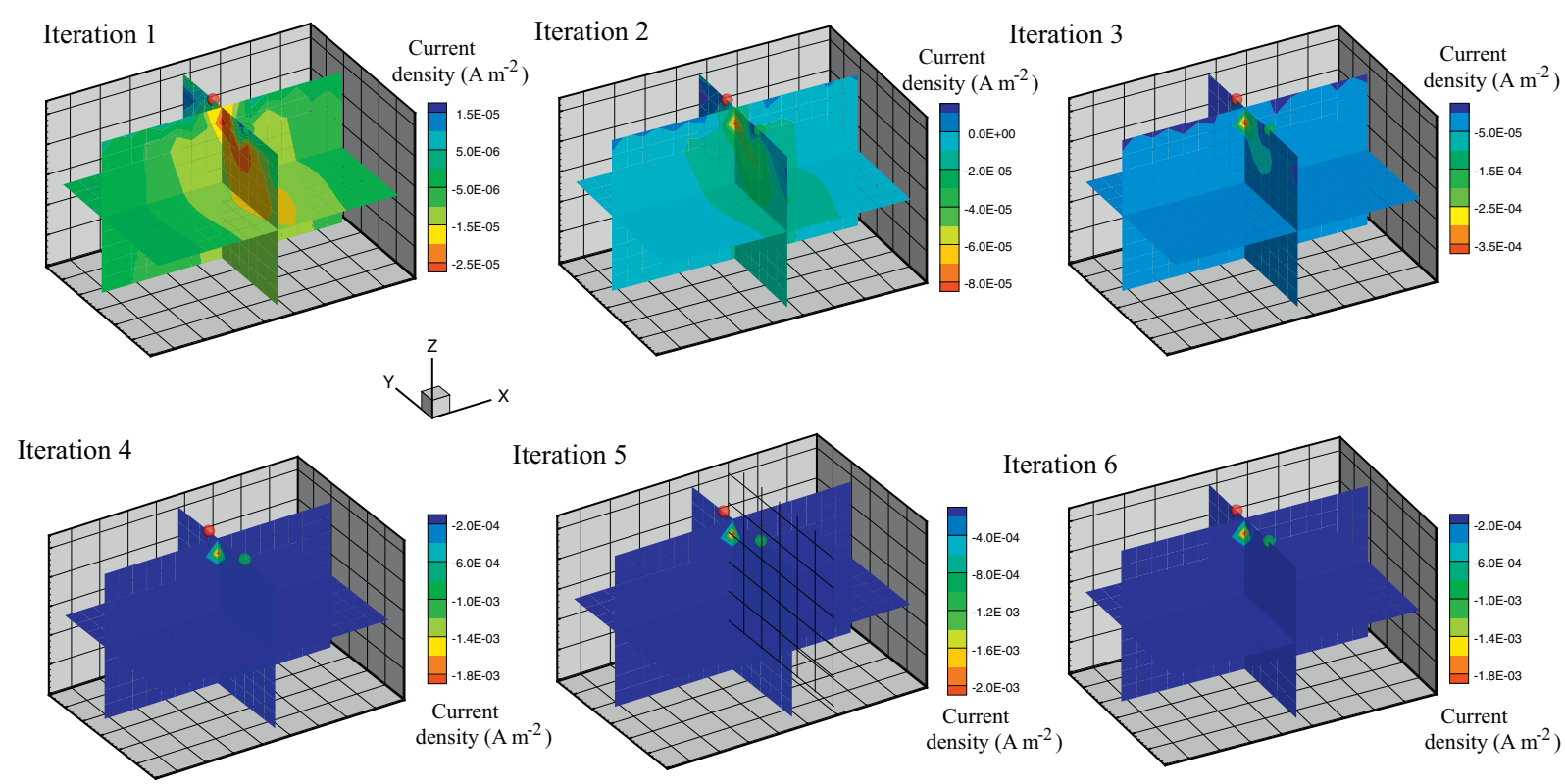

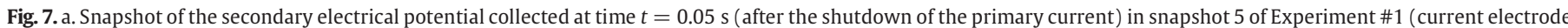

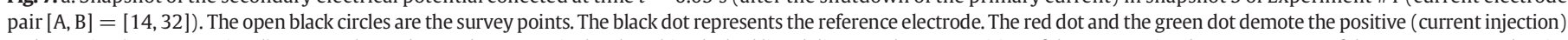

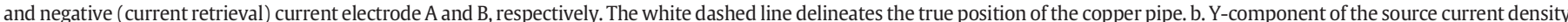

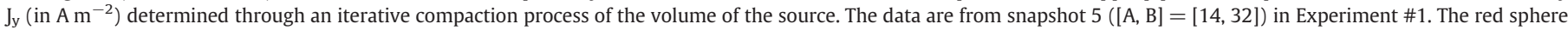

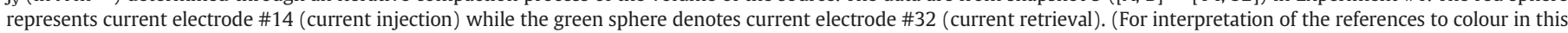
figure legend, the reader is referred to the web version of this article.) 


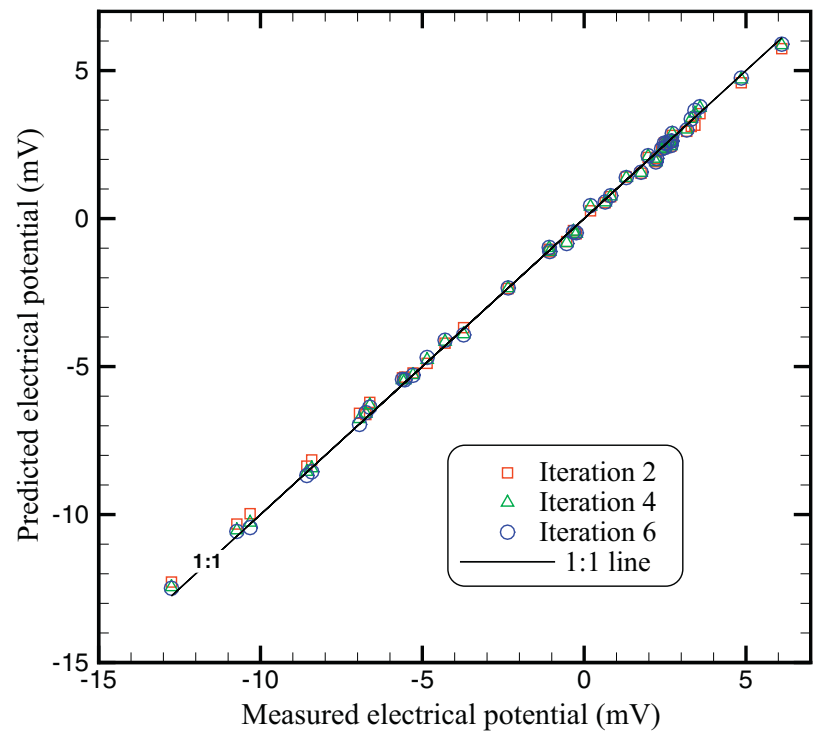

Fig. 8. The comparison between measured and estimated electrical potential data at different iterations for snapshot 5 in the first experiment.

position of the source. After only 5 iterations, the retrieved source is compact and the data misfit is stable. The source current locates at the position where the source is originally set up in the model. At iteration
6 , the value of the compacted source current density is $0.09 \mathrm{~A} \mathrm{~m}^{-2}$, very close to the true value used in the modeling $\left(0.10 \mathrm{~A} \mathrm{~m}^{-2}\right)$. This indicates that our approach is efficient to invert the electrical potential data in terms of source current density distribution.

\subsection{Inversion of the laboratory data}

Regarding the laboratory data, we need also a temporal reference (e.g., Linde et al., 2007). Therefore, the secondary voltages at all windows and for each test are referenced to the voltage measured at the last window (i.e., at $t=5.13 \mathrm{~s}$ ). Indeed, we assume that at this time the secondary voltages have fully relaxed, i.e., the electrical potentials are assumed to have decayed to zero (this will be discussed further at the end of this paper).

Before inverting the secondary electrical potential data (shown in Fig. 5), we need to get the electrical resistivity distribution inside the tank to calculate the kernel matrix. Therefore, the resistivity data should be inverted first by using the resistance data collected during the induced polarization test, i.e., using the primary electrical fields measured during the injection of the primary current (see Fig. 2). This is a classical method in geophysics called electrical resistivity (or resistance) tomography. The inversion algorithm used for resistivity tomography in this paper was developed by Mao et al. (2015) using Matlab and Comsol Multiphysics and the Application Programming Interface (API) functions. The domain was discretized into $20 \times 12 \times 12=2880$ cells in $x, y$ and $z$ directions covering the volume of the tank. This means the model vector $\mathbf{m}$ for the resistivity
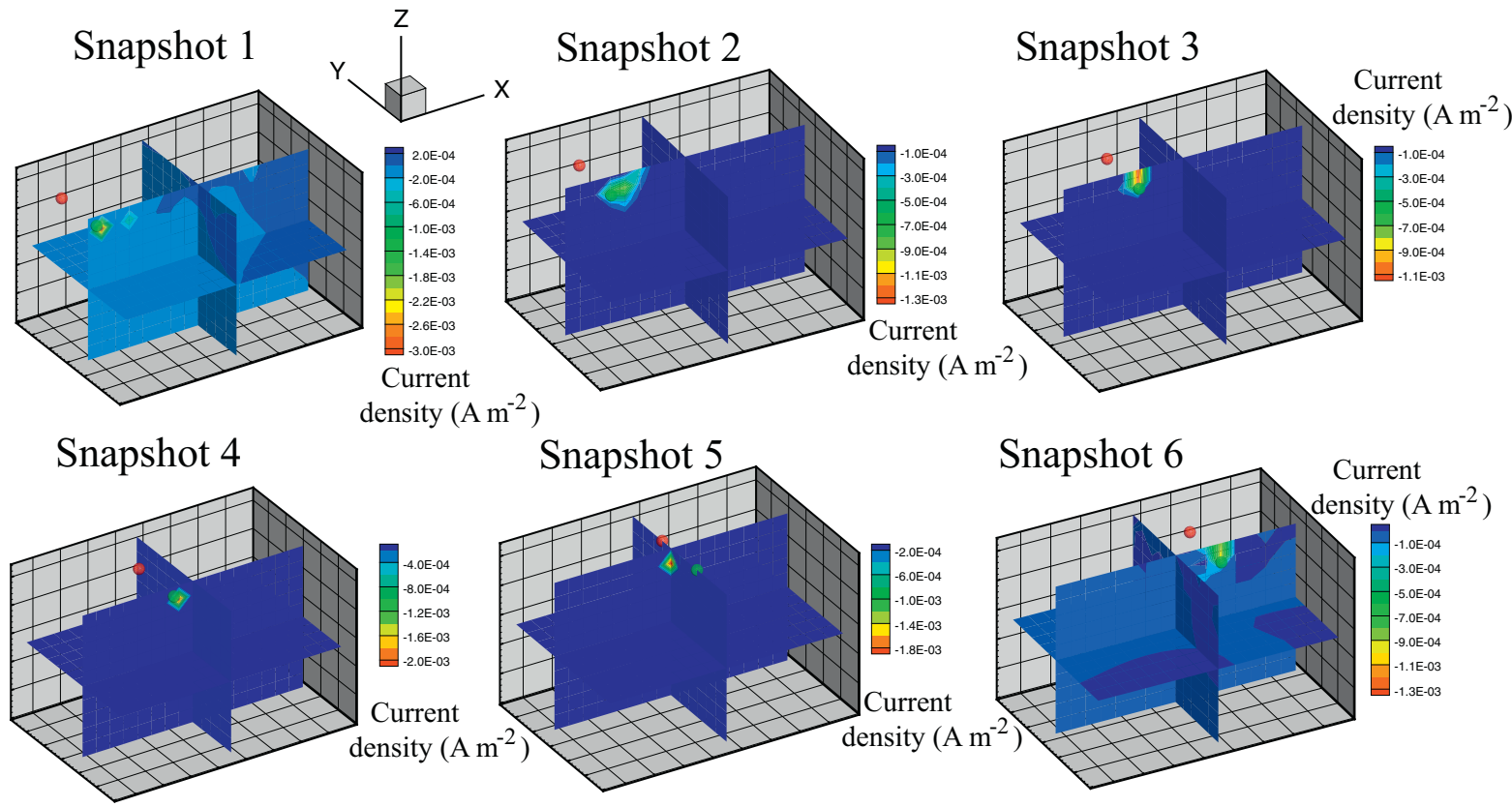

density $\left(\mathrm{A} \mathrm{m}^{-2}\right)$
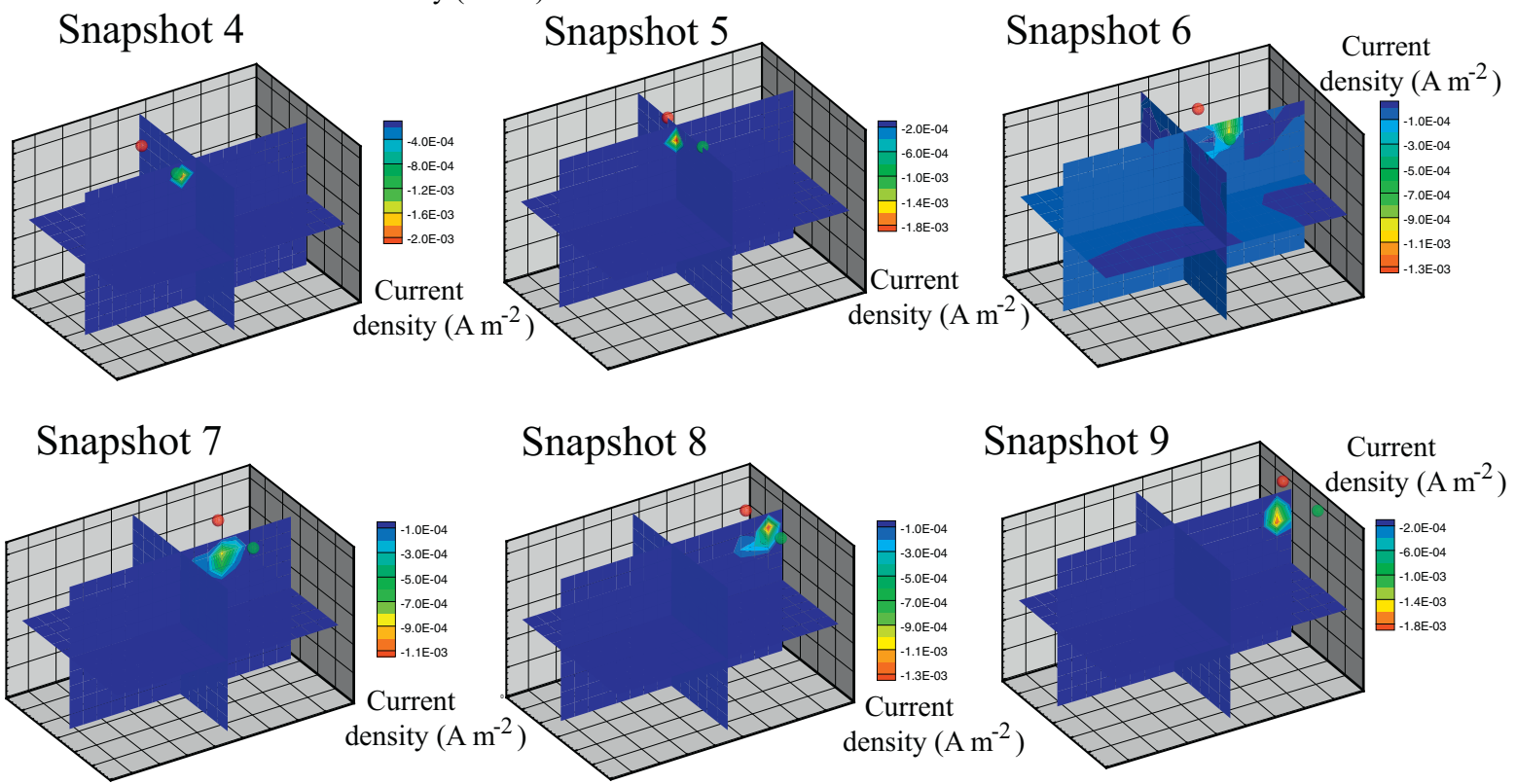

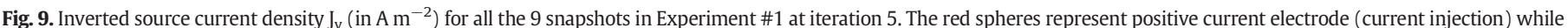

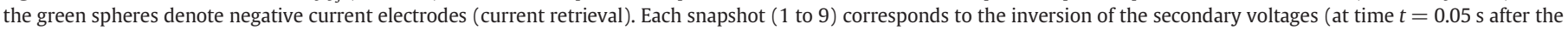

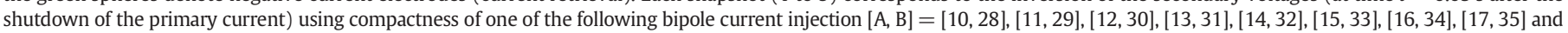
$[18,36]$. (For interpretation of the references to colour in this figure legend, the reader is referred to the web version of this article.) 
problem contains 2880 unknown electrical resistivity values. The 3D inverted resistivity tomogram is shown in Fig. 6. Note that the inversion accounts for the insulating boundary conditions at the tank boundaries. Because of the lack of resolution of this method, resistivity does not show the position of the pipe (as expected) but is required for the computation of the kernel as mentioned above. Also another reason why the pipe is not detected by ERT is that resistivity analyzes the electrical field at very low frequencies. At shown in Fig. 1, at low frequencies the excitation of the pipe in the normal direction implies that the charge carriers will be blocked by the boundaries of the pipe itself. So the pipe may appear as an insulating body at low frequencies as shown in the laboratory experiments discussed by Revil et al. (2015b). Imaging an insulating body in a conductive environment is a notoriously difficult task since the current lines are going to go around the target. This is why induced polarization is more appealing than electrical resistivity tomography in localizing the metallic pipe.

For the inversion of the secondary electrical potential data, the domain includes a total of 1600 cells $(16 \times 10 \times 10$ cells in $x, y$ and $z$ directions, respectively). Since the kernel values were defined on the node, there were a total of 2057 nodes $(17 \times 11 \times 11$ nodes in $x, y$ and $z$ directions, respectively) for placing the dipole sources. The dimension of the kernel was therefore $42 \times 6171$ for each test. We have there 42 measurements and $2057 \times 3=6171$ unknown source current density in $x, y$ and $z$ directions, 2057 unknowns if we consider only a $y$-component normal to the pipe.

\section{Results}

\subsection{Experiment \#1}

Fig. 5 shows the secondary voltage distribution at few selected electrodes collected in snapshot \#5 $([\mathrm{A}, \mathrm{B}]=[14,32])$ of Experiment 1 . All of the data at electrodes \#2 to \#9 (located at one side of the copper pipe in the $y$-direction normal to the pipe) are negative. At the opposite, all of the data at electrodes \#28 to \#36 (located on the other side of the copper pipe) are positive. These evidences indicate that the secondary electrical potentials are generated by a horizontal (in the $y$-direction) secondary source current density. Furthermore, the data with largest amplitude are collected near the two current injection electrodes.

Fig. 7a shows an equipotential map of the secondary electrical potential collected at time $t=0.05 \mathrm{~s}$ after the shutdown of the primary current in snapshot 5 (current electrode pair $[A, B]=[14,32]$ ). From this potential distribution, a clear source is expected close to the center of the bipole $[A, B]=[14,32]$. Fig. $7 \mathrm{~b}$ shows the iterative compaction procedure of the source current density ( $y$-component) for snapshot 5. The source current density is shown at iterations 1 to 6 in the compaction process. For each snapshot, the red sphere denotes the positive current electrode and the green sphere denotes the negative current electrode. During the inversion, the source current density focuses in the center of the bipole. After only 5 iterations, the source current density is compact and well localized in the tank. We can also clearly see that the value of compact source current has a direction that is opposite to the direction of the primary current density (see Fig. 1 where similarly the secondary electrical field is in the direction opposite to the primary electrical field).

The comparison between measured and estimated electrical potential data for snapshot 5 at different iterations is shown in Fig. 8. The estimated data reproduces the real data very well and the selfpotential data are well-recovered by the inversion algorithm. Fig. 9 is the inverted source current density for all the 9 snapshots. The source current densities are always localized around the target as expected. Finally, the source current density distributions obtained from all the 9 bipoles $[A, B]$ are averaged to recover the geometry of the copper pipe. In Fig. 10a, we plot the isosurface distribution of the averaged source current density (normalized with respect to the primary current density) together with the true position of the copper pipe. The source current density distributes around the copper pipe and is therefore able to image the true position of the pipe.

In Fig. 10b, we repeat the same exercise at a later time. We chose the time $0.17 \mathrm{~s}$ after the shutdown of the primary current. Again the same conclusion can be reached regarding the adequacy between the position of the source of current and the true position of the pipe.

\subsection{Experiment \#2}

The final inverted source current densities for the 7 snapshots are shown in Fig. 11 in the case of Experiment \#2. We can observe that the position of the source current density moves along the current bipole and gets deeper from left to right. In order to recover the geometry of the stainless steel pipe, we combine all the data from the 7 snapshots. As shown in Fig. 11, the value of the inverted source current density in each snapshot differs. Therefore, we don't use the source current density directly to recover the geometry of the pipe. Instead, we

\section{Pipe localization (Experiment \#1)}
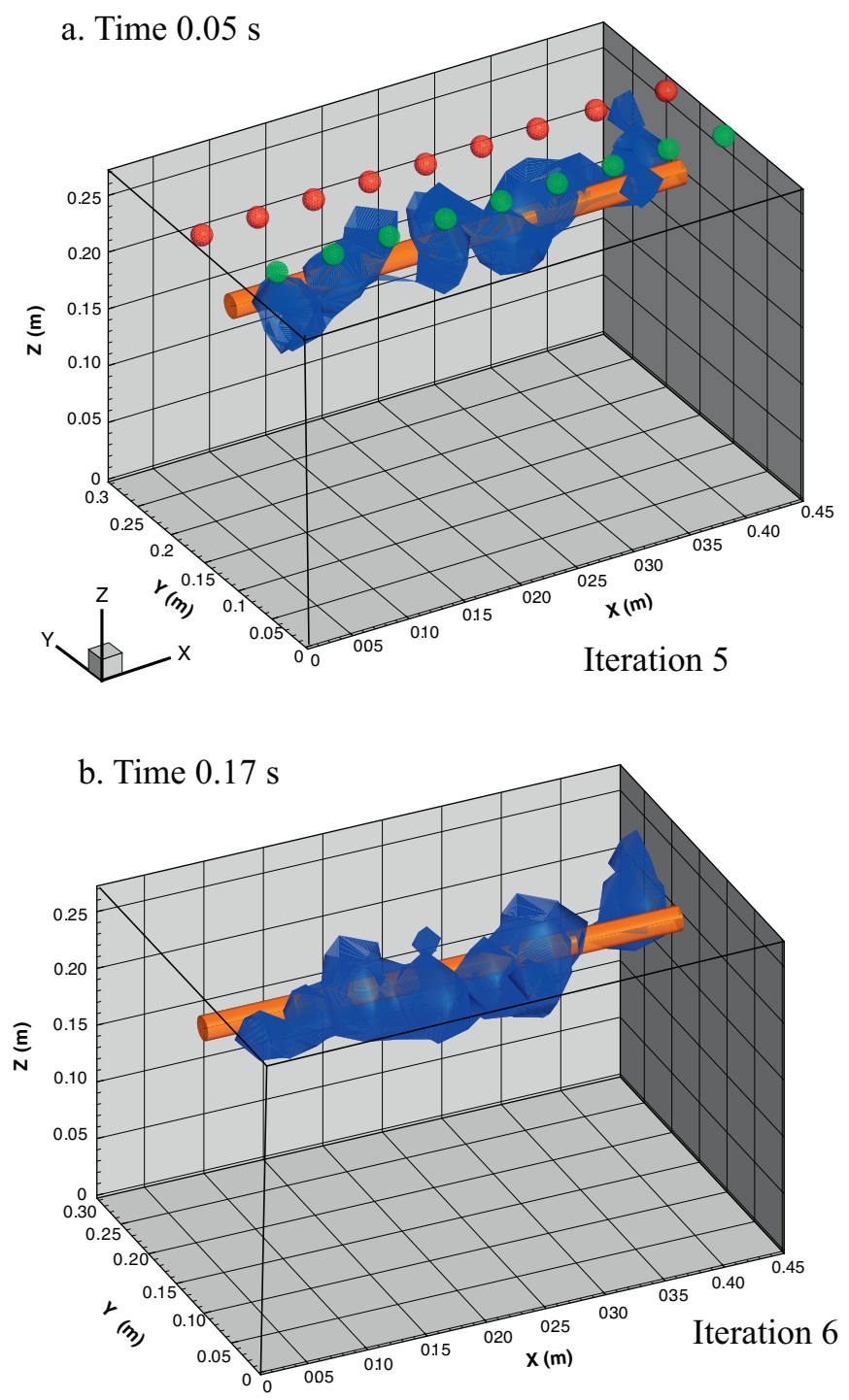

Fig. 10. Iso-surface distribution of the averaged source current density ( $y$-component) for all the 9 snapshots in Experiment \#1 at iteration 5 in the compaction process (the secondary current is here normalized to the primary current density). The brassy cylinder denotes the copper pipe. a. The secondary voltages are inverted at time $t=$ $0.05 \mathrm{~s}$ after the shutdown of the primary current. b. Same work at $0.17 \mathrm{~s}$ after the shutdown of the primary current. 

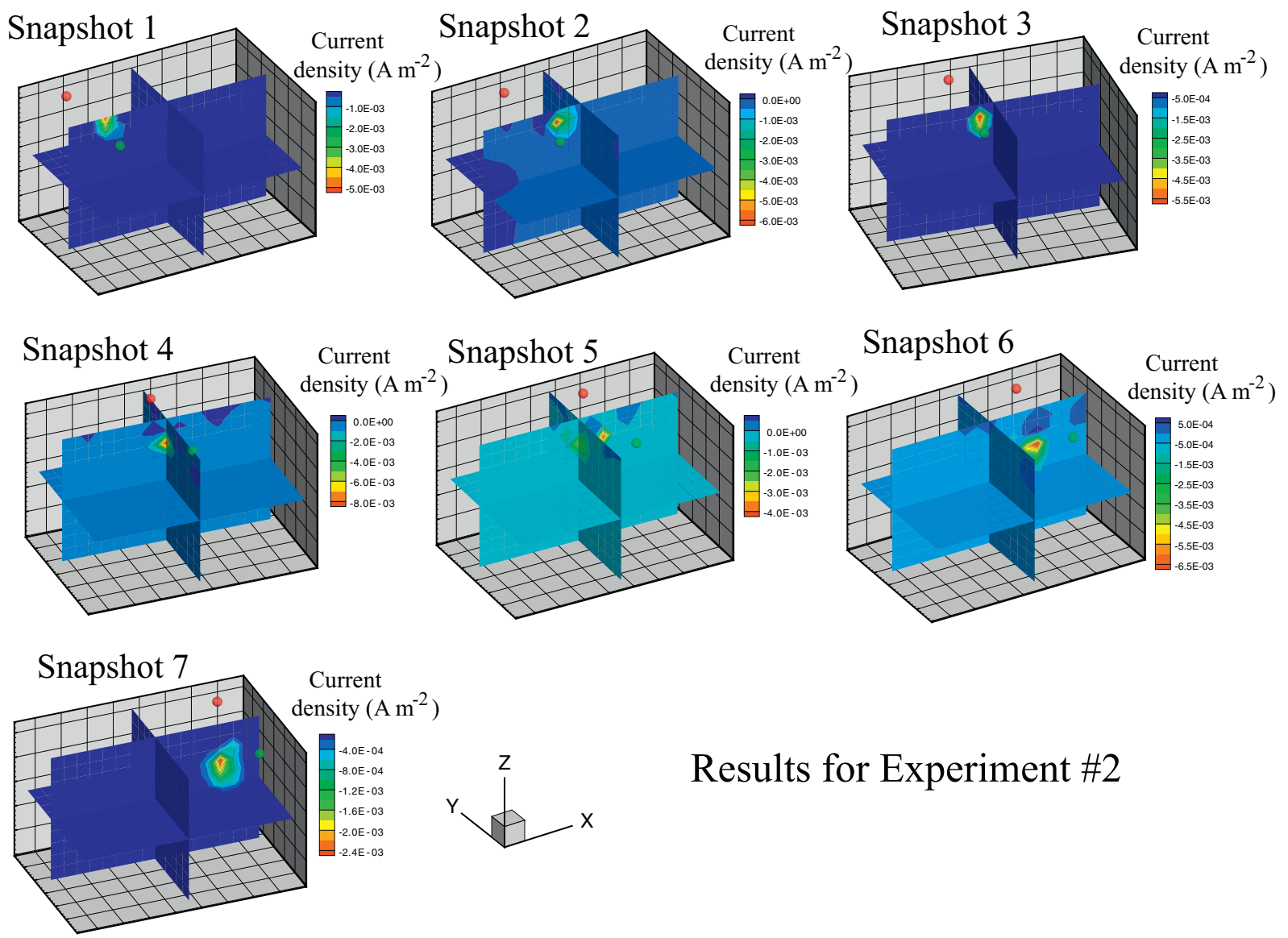

\section{Results for Experiment \#2}

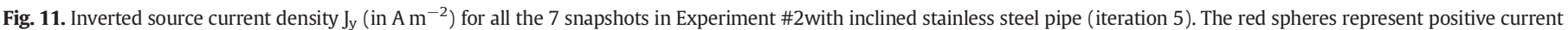

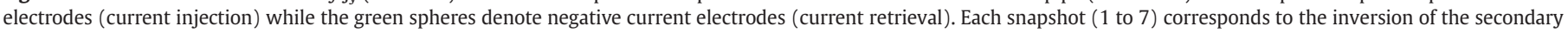

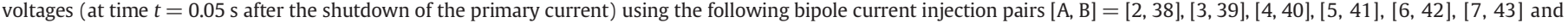
$[8,44]$. (For interpretation of the references to colour in this figure legend, the reader is referred to the web version of this article.)

first normalize it by dividing the minimum value ( since $\mathrm{J}_{\mathrm{y}}$ is negative) in each snapshot, and then average the normalized $\mathrm{J}_{\mathrm{y}}$ from all the 7 snapshots. Fig. 12 shows the isosurface distribution of the averaged normalized source current density. The true position of the stainless steel pipe is surrounded by the retrieved source current density isosurface. The inverted pipe position shows a fair agreement with its true position.

\subsection{Relaxation time}

The secondary voltage decays are shown in Fig. 13 for selected electrodes. We first see that the potentials have fully relaxed or so at time $t=5.13 \mathrm{~s}$ after the shutdown of the primary current. The data can be approximately fitted by an exponential decay characterized by a relaxation time. This relaxation time can be related to the characteristic grain size, $a$, of the metallic pipe by $\tau_{0}=a^{2} / D$, where $D\left(\right.$ in $\left.\mathrm{m}^{2} \mathrm{~s}^{-1}\right)$ denotes an apparent diffusion coefficient of the charge carriers (see Revil et al., 2015a, b; Mao and Revil, 2016 for disseminated metallic grains). We fitted an exponent decay to the data shown in Fig. 1). The relaxation time is approximately $0.50 \pm 0.15 \mathrm{~s}$ for a pipe radius of $1 \mathrm{~cm}$ (for both Experiments \#1 an \#2). As shown in Fig. 14, these data are consistent with other data usually based on disseminated metallic particles in sands and slags (including data from references Grissemann et al., 2000; Nordsiek and Weller, 2008; Florsch et al., 2011; Mao and Revil, 2016). The trend shown in Fig. 14 indicates that the mean value of the diffusion coefficient is $D=0.028 \mathrm{~m}^{2} \mathrm{~s}^{-1}(25$ ${ }^{\circ} \mathrm{C}$ ). This means that in field conditions, we could use the information contained in the relaxation time to get an idea of the radius of the pipe.

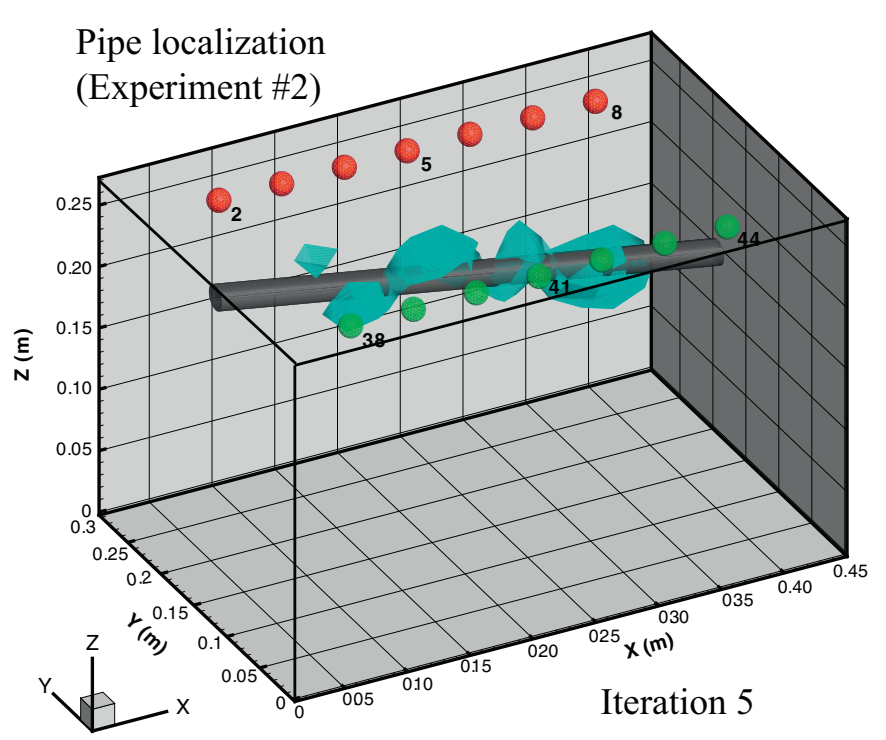

Fig. 12. Iso-surface distribution of the averaged normalized source current density (Jy) of all the 7 snapshots in Experiment \#2. The dark gray cylinder denotes the inclined stainless steel pipe. The value of the isosurface is 0.043 (arbitrary units). The red and green spheres represent the 7 bipoles $[A, B]$, respectively. Note that the density distributes around the two ends of the pipe is not resolved because that we do not have current electrode pairs investigating these areas. The secondary voltages are inverted at time $t=0.05 \mathrm{~s}$ after the shutdown of the primary current. (For interpretation of the references to colour in this figure legend, the reader is referred to the web version of this article.) 
a. Secondary voltage decay (Experiment \#1)

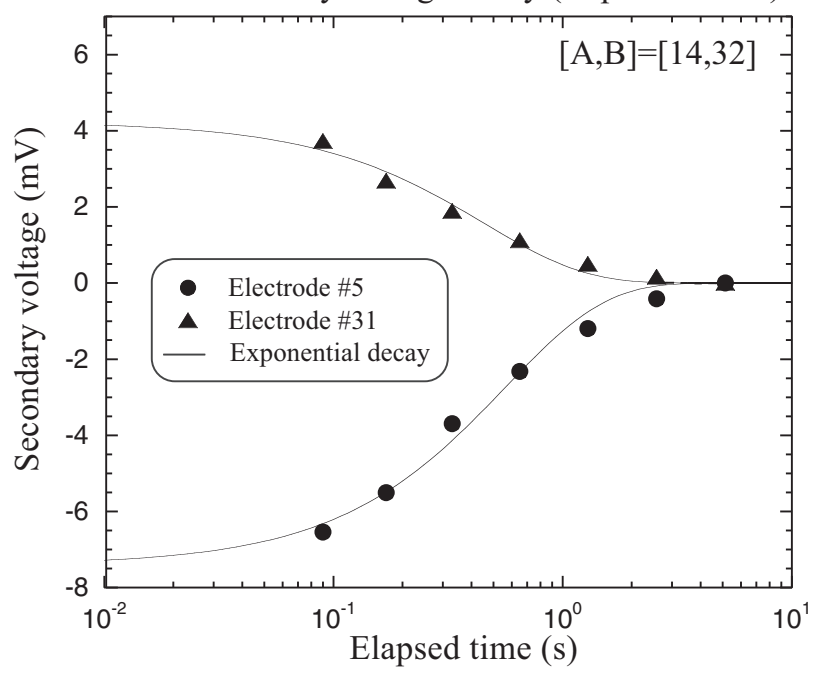

b. Secondary voltage decay (Experiment \#2)

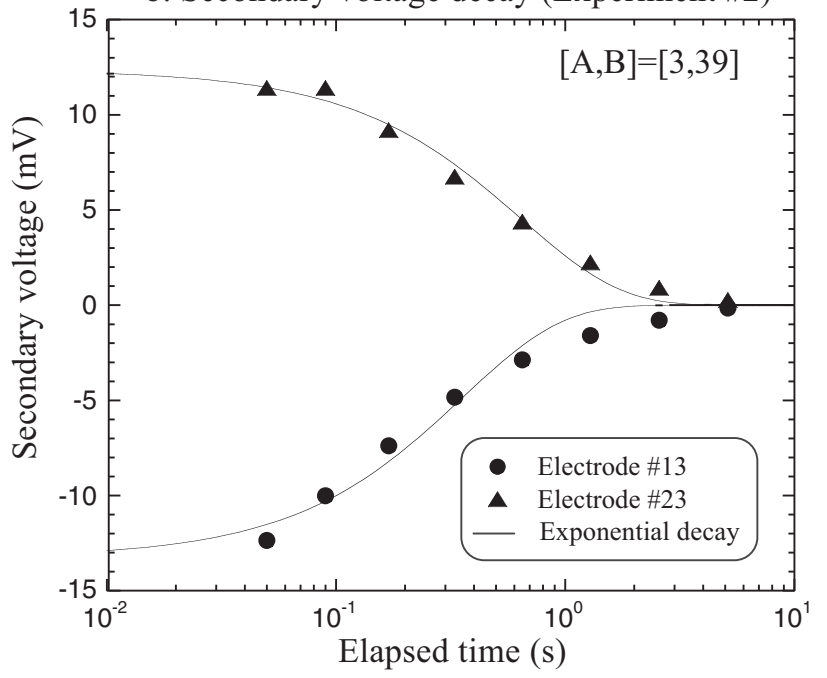

Fig. 13. Secondary voltages fitted by exponential decay functions. a. Voltage decay for Experiment \#1 (snapshot based on $[\mathrm{A}, \mathrm{B}]=[14,32])$, The voltage electrodes are \#5 (relaxation time $\left.\tau_{0}=0.56 \mathrm{~s}, \mathrm{R}=0.99\right)$ and electrode \#31 $\left(\tau_{0}=0.46 \mathrm{~s}, \mathrm{R}=0.99\right.$ ). b. Voltage decay for Experiment \#2 (snapshot based on $[A, B]=[3,39])$, The voltage electrodes are \#13 (relaxation time $\tau_{0}=0.35 \mathrm{~s}, \mathrm{R}=0.98$ ) and electrode \#23 $\left(\tau_{0}=0.64 \mathrm{~s}, \mathrm{R}=0.99\right)$.

\section{Conclusions}

Our goal was to test the effectiveness of a new non-intrusive method to localize underground metallic pipes. Two sandboxes were designed to conduct experiment with a horizontal copper pipe (Experiment \#1) and an inclined stainless steel pipe (Experiment \#2). We invert here the secondary voltages and compact the causative current source using algorithms that are similar to those developed in electroencephalography. The following conclusions have been reached:

(1) The synthetic test indicates that our algorithm is efficient in retrieving the position and magnitude of a source current distribution located at depth in a conductive environment.

(2) The presence of a metallic pipe generates a very clear secondary self-potential anomaly on the surface of a sandbox after the primary current is shut down.

(3) No resistivity anomaly is observed on the resistivity tomogram from both experiments. The electrical resistivity tomography seems not sensitive enough to locate the buried metallic pipes. Indeed at low frequencies a conductive pipe can appear resistive

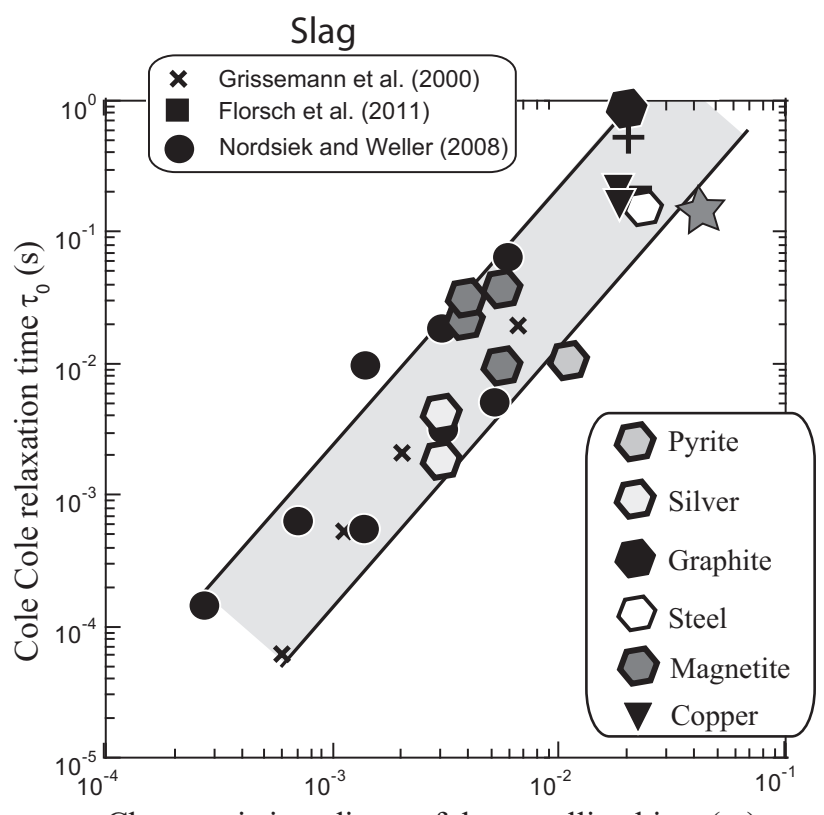

Characteristic radius $a$ of the metallic object (m)

Fig. 14. Relaxation time $\tau$ versus the characteristic size of the metallic object. The star corresponds to an unpublished sandbox experiment with the relaxation time given by fitting the secondary voltages with an exponential decay and the metallic objet is a copper plate. In this case, we used the radius of an equivalent sphere. The trend (in gray) shown by the data can be captured by an apparent diffusion coefficient $D=$ $0.028 \mathrm{~m}^{2} \mathrm{~s}^{-1}\left(25^{\circ} \mathrm{C}\right)$. Experiment \#1 and \#2 with a pipe radius of $1 \mathrm{~cm}$ and a mean relaxation time of $0.5 \mathrm{~s}$ is shown by the " + " symbol.

if the current is applied perpendicularly to the pipe direction. The reason is that at low-frequencies, the pipe can be totally polarized and the charge carriers re blocked at the boundaries of the metallic body.

(4) The recovered source current density is consistent with the true position of the metallic pipes whatever their direction. The result indicates that this novel method could be applied to localize accurately underground metallic pipes.

(5) The relaxation time contains some information regarding the radius of the pipe.

Future works will concern the use of principal component analysis to discriminate between the signals associated with several pipes and the use of more sophisticated delineation image processing technique to underline the position of the pipe from the inverted signals. A comparison between the proposed techniques and other method would be interesting in order to see if these methods can be applied in concert in better localizing metallic pipes in the ground.

\section{Acknowledgement}

Zhenlu Shao thanks the financial support of the China Scholarship Council (201506420023). We also thank the Joint Funds of the National Natural Science Foundation of China and the Shenhua Group Corporation Limited (No. 51134020), the Research and Innovation Program for College Graduates of Jiangsu Province (No. KYLX_1412), and the Priority Academic Program Development of Jiangsu Higher Education Institutions (PAPD). We thank the editor and three anonymous referees for their comments.

\section{References}

Al-Nuaimy, W., Huang, Y., Nakhkash, M., Fang, M., Nguyen, V., Eriksen, A., 2000. Automatic detection of buried utilities and solid objects with GPR using neural networks and 
pattern recognition. J. Appl. Geophys. 43:157-165. https://doi.org/10.1016/S09269851(99)00055-5.

Ayala-Cabrera, D., Herrera, M., Izquierdo, J., Pérez-García, R., 2011. Location of buried plastic pipes using multi-agent support based on GPR images. J. Appl. Geophys. 75: 679-686. https://doi.org/10.1016/j.jappgeo.2011.09.024.

Bernstein, R., Oristaglio, M., Miller, D., Haldorsen, J., 2000. Imaging radar maps underground objects in 3-D. IEEE Comput. Appl. Pow. 13:20-24. https://doi.org/10.1109/ 67.849021 .

Costello, S., Chapman, D., Rogers, C., Metje, N., 2007. Underground asset location and condition assessment technologies. Tunn. Undergr. Space Technol. 22:524-542. https:// doi.org/10.1016/j.tust.2007.06.001.

Doetsch, J., Fiandaca, G., Auken, E., Christiansen, A.V., Cahill, A.G., Jakobsen, R., 2015. Fieldscale time-domain spectral induced polarization monitoring of geochemical changes induced by injected $\mathrm{CO}_{2}$ in a shallow aquifer. Geophysics 80:WA113-WA126. https:// doi.org/10.1190/geo2014-0315.1.

Dziadak, K., Kumar, B., Sommerville, J., 2009. Model for the 3D location of buried assets based on RFID technology. J. Comput. Civ. Eng. 23:148-159. https://doi.org/ 10.1061/(ASCE)0887-3801(2009)23:3(148).

Fedde, P., Patterson, C., 1988. Locator continuously records pipeline depth readings. Oil Gas J. 86.

Florsch, N., Llubes, M., Téreygeol, F., Ghorbani, A., Roblet, P., 2011. Quantification of slag heap volumes and masses through the use of induced polarization: application to the Castel-Minier site. J. Archaeol. Sci. 38:438-451. https://doi.org/10.1016/j. jas.2010.09.027

Gazoty, A., Fiandaca, G., Pedersen, J., Auken, E., Christiansen, A.V., 2012. Mapping of landfills using time-domain spectral induced polarization data: the Eskelund case study. Near Surf. Geophys. 10:575-586. https://doi.org/10.3997/1873-0604.2012046.

Goodman, D., 1994. Ground-penetrating radar simulation in engineering and archaeology Geophysics 59 (2):224-232. https://doi.org/10.1190/1.1443584.

Grandjean, G., Gourry, J., Bitri, A., 2000. Evaluation of GPR techniques for civil-engineering applications: study on a test site. J. Appl. Geophys. 45:141-156. https://doi.org/ 10.1016/S0926-9851(00)00021-5.

Grech, R., Cassar, T., Muscat, J., Camilleri, K.P., Fabri, S.G., Zervakis, M., Xanthopoulos, P. Sakkalis, V., Vanrumste, B., 2008. Review on solving the inverse problem in EEC source analysis. J. Neuroeng. Rehabil. 5 (25):1-33. https://doi.org/10.1186/17430003-5-25.

Grissemann, C., Rammlmair, D., Siegwart, C., Fouillet, N., 2000. Spectral induced polarization linked to image analyses: a new approach. In: Rammlmair, D., Mederer, J., Oberthür, T., Heimann, R., Pentinghaus, H. (Eds.), Applied Mineralogy. Balkema, pp. 561-564.

Haas, A., Revil, A., Karaoulis, M., Frash, L., Hampton, J., Gutierrez, M., Mooney, M., 2013. Electric potential source localization reveals a borehole leak during hydraulic fracturing. Geophysics 78:D93-D113. https://doi.org/10.1190/geo2012-0388.1.

Ikard, S.J., Revil, A., Jardani, A., Woodruff, W.F., Parekh, M., Mooney, M., 2012. Saline pulse test monitoring with the self-potential method to nonintrusively determine the velocity of the pore water in leaking areas of earth dams and embankments. Water Resour. Res. 48, W04201. https://doi.org/10.1029/2010WR010247.

Janning, R., Horváth, T., Busche, A., Schmidt-Thieme, L., 2012. Pipe localization by apex detection. Proceedings Radar Systems (Radar 2012), IET International Conference. IET, pp. 1-6.

Jardani, A., Revil, A., Bolève, A., Dupont, J., 2008. Three-dimensional inversion of selfpotential data used to constrain the pattern of groundwater flow in geotherma fields. J. Geophys. Res.:113 https://doi.org/10.1029/2007JB005302.

Jeong, H.S., Abraham, D.M., 2004. A decision tool for the selection of imaging technologies to detect underground infrastructure. Tunn. Undergr. Space Technol. 19:175-191. https://doi.org/10.1016/j.tust.2003.09.001.

Kemna, A., Binley, A., Slater, L., 2004. Crosshole IP imaging for engineering and environmental applications. Geophysics 69:97-107. https://doi.org/10.1190/1.1649379.

Kemna, A., Binley, A., Cassiani, G., Niederleithinger, E., Revil, A., Slater, L., Williams, K.H. Orozco, A.F., Haegel, F.-H., Hoerdt, A., 2012. An overview of the spectral induced polarization method for near-surface applications. Near Surf. Geophys. 10, 453-468.

Last, B., Kubik, K., 1983. Compact gravity inversion. Geophysics 48:713-721. https://doi. org/10.1190/1.1441501.

Leroy, P. Revil, A., Kemna, A., Cosenza, P., Ghorbani, A, 2008. Complex conductivity of water-saturated packs of glass beads. J. Colloid Interface Sci. 321 (1):103-117. https://doi.org/10.1016/j.jcis.2007.12.031.

Linde, N., Jougnot, D., Revil, A., Matthaï, S.K., Arora, T., Renard, D., Doussan, C., 2007. Streaming current generation in two-phase flow conditions. Geophys. Res. Lett. 34 (3), L03306. https://doi.org/10.1029/2006GL028878.

Loeb, J., Bertin, J., 1976. Experimental and Theoretical Aspects of Induced Polarization: Macroscopic and Mictroscopic Theories. Gebrüder Borntraeger.
Mao, D., Revil, A., 2016. Induced polarization response of porous media with metallic particles. - part 3. A new approach to time- domain induced polarization tomography. Geophysics 81:D345-D357. https://doi.org/10.1190/geo2015-0283.1.

Mao, D., Revil, A., Hort, R., Munakata-Marr, J., Atekwana, E., Kulessa, B., 2015. Resistivity and self-potential tomography applied to groundwater remediation and contaminant plumes: sandbox and field experiments. J. Hydrol. 530:1-14. https://doi.org/10.1016/ j.jhydrol.2015.09.031.

Muggleton, J., Brennan, M., 2004. Leak noise propagation and attenuation in submerged plastic water pipes. J. Sound Vib. 278:527-537. https://doi.org/10.1016/j. jsv.2003.10.052.

Naudet, V., Revil, A., 2005. A sandbox experiment to investigate bacteria-mediated redox processes on self-potential signals. Geophys. Res. Lett. 32, L11405. https://doi.org/ 10.1029/2005GL022735.

Nordsiek, S., Weller, A., 2008. A new approach to fitting induced-polarization spectra. Geophysics 73 (6):F235-F245. https://doi.org/10.1190/1.2987412.

Olhoeft, G.R., 2000. Maximizing the information return from ground penetrating radar. J. Appl. Geophys. 43:175-187. https://doi.org/10.1016/S0926-9851(99)00057-9.

Pettinelli, E., Di Matteo, A., Mattei, E., Crocco, L., Soldovieri, F., Redman, J.D., Annan, A.P., 2009. GPR response from buried pipes: measurement on field site and tomographic reconstructions. IEEE Trans. Geosci. Remote 47:2639-2645. https://doi.org/10.1109/ TGRS.2009.2018301.

Qi, J., 2016. Complement the weakness of underground development in urban area. Chinese People's Political Consultative Conference. 7, p. 14 (In Chinese).

Revil, A., Karaoulis, M., Johnson, T., Kemna, A., 2012. Review: some low-frequency electrical methods for subsurface characterization and monitoring in hydrogeology. Hydrogeol. J. 20:617-658. https://doi.org/10.1007/s10040-011-0819-x.

Revil, A., Karaoulis, M., Srivastava, S., Byrdina, S., 2013. Thermoelectric self-potential and resistivity data localize the burning front of underground coal fires. Geophysics 78 (5), B259-B273.

Revil, A., Florsch, N., Mao, D., 2015a. Induced polarization response of porous media with metallic particles-part 1: a theory for disseminated semiconductors. Geophysics 80: D525-D538. https://doi.org/10.1190/geo2014-0577.1.

Revil, A., Abdel Aal, G.Z., Atekwana, E.A., Mao, D., Florsch, N., 2015b. Induced polarization response of porous media with metallic particles-part 2. Comparison with a broad database of experimental data. Geophysics 80 (5):D539-D552. https://doi.org/ 10.1190/GEO2014-0578.1.

Revil, A., Sleevi, M.F., Mao, D., 2017a. Induced polarization response of porous media with metallic particles - part 5. Influence of the background polarization. Geophysics 82 (2):E77-E96. https://doi.org/10.1190/geo2016-0388.1.

Revil, A., Mao, D., Shao, Z., Sleevi, M.F., Wang, D., 2017b. Induced polarization response of porous media with metallic particles - part 6 . The case of metals and semi-metals. Geophysics 82 (2):E97-E110. https://doi.org/10.1190/geo2016-0389.1.

Rittgers, J., Revil, A., Karaoulis, M., Mooney, M., Slater, L., Atekwana, E., 2013. Self-potential signals generated by the corrosion of buried metallic objects with application to contaminant plumes. Geophysics 78:EN65-EN82. https://doi.org/10.1190/geo20130033.1.

Schlumberger, C., 1920. Study of Underground Electrical Prospecting, Paris (99 pp).

Seigel, H., Nabighian, M., Parasnis, D.S., Vozoff, K., 2007. The early history of the induced polarization method. Lead. Edge 26:312-321. https://doi.org/10.1190/1.2715054.

Slater, L.D., Lesmes, D., 2002. IP interpretation in environmental investigations. Geophysics 67:77-88. https://doi.org/10.1190/1.1451353.

Soueid Ahmed, A., Jardani, A., Revil, A., Dupont, J.P., 2013. SP2DINV: a 2D forward and inverse code for streaming-potential problems. Comput. Geosci. 59, 9-16.

Sun, Z., Wang, P., Vuran, M.C., Al-Rodhaan, M.A., Al-Dhelaan, A.M., Akyildiz, I.F., 2011. MISE-PIPE: magnetic induction-based wireless sensor networks for underground pipeline monitoring. Ad Hoc Netw. 9:218-227. https://doi.org/10.1016/j. adhoc.2010.10.006.

Tong, L., 1997. Ground penetrating radar applied in locating underground pipes. Proceedings of the 15 International No-Dig. 97

Vanhala, H., Soininen, H., Kukkonen, I., 1992. Detecting organic chemical contaminants by spectral-induced polarization method in glacial till environment. Geophysics 57: 1014-1017. https://doi.org/10.1190/1.1443312.

Vickridge, I., Leontidis, D., 1997. Sewer surveys. Sewers-Rehabilitation and Construction. 1:pp. 84-102. https://doi.org/10.1016/B978-034054472-3/50008-8.

Wirahadikusumah, R., Abraham, D.M., Iseley, T., Prasanth, R.K., 1998. Assessment technologies for sewer system rehabilitation. Autom. Constr. 7:259-270. https://doi.org/ 10.1016/S0926-5805(97)00071-X.

Wong, J., 1979. An electrochemical model of the induced polarization phenomenon in disseminated sulfide ores. Geophysics 44 (7), 1245-1265. 